\title{
Higher Sea Levels at Hawaii Caused by Strong EI Niño and Weak Trade Winds
}

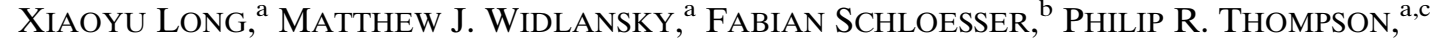 \\ H. ANNAMAlai, ${ }^{\mathrm{b}, \mathrm{c}}$ Mark A. Merrifield,${ }^{\mathrm{d}}$ AND Hyang YOON ${ }^{\mathrm{c}}$ \\ ${ }^{a}$ Joint Institute for Marine and Atmospheric Research, School of Ocean and Earth Science and Technology, University of \\ Hawai' 'i at Mānoa, Honolulu, Hawaii \\ ${ }^{\mathrm{b}}$ International Pacific Research Center, University of Hawai'i at Mānoa, Honolulu, Hawaii \\ ${ }^{\mathrm{c}}$ Department of Oceanography, University of Hawai'i at Mānoa, Honolulu, Hawaii \\ ${ }^{\mathrm{d}}$ Scripps Institution of Oceanography, University of California, San Diego, La Jolla, California
}

(Manuscript received 21 March 2019, in final form 3 January 2020)

\begin{abstract}
Hawaii experienced record-high sea levels during 2017, which followed the 2015 strong El Niño and coincided with weak trade winds in the tropical northeastern Pacific. The record sea levels were associated with a combination of processes, an important contributing factor of which was the persistent high sea level ( $\sim 10 \mathrm{~cm}$ above normal) over a large region stretching between Hawaii and Mexico. High sea levels at Mexico are known to occur during strong El Niño as the coastal thermocline deepens. Planetary wave theory predicts that these coastal anomalies propagate westward into the basin interior; however, high sea levels at Hawaii do not occur consistently following strong El Niño events. In particular, Hawaii sea levels remained near normal following the previous strong El Niño of 1997. The processes controlling whether Hawaii sea levels rise after El Niño have so far remained unknown. Atmosphere-forced ocean model experiments show that anomalous surface cooling, controlled by variable trade winds, impacts sea level via mixed layer density, explaining much of the difference in Hawaiian sea level response after the two recent strong El Niño events. In climate model projections with greenhouse warming, more frequent weak trade winds following El Niño events are expected, suggesting that the occurrence of high sea levels at Hawaii will increase as oceanic anomalies more often traverse the basin.
\end{abstract}

\section{Introduction}

Record-high sea levels occurred in the Hawaiian Islands during 2017 (Fig. 1a) and contributed to minor recurrent flooding of coastal areas. High water levels began in 2016 and peaked during April and August 2017 when many days experienced levels $20-30 \mathrm{~cm}$ above the daily highest astronomical tidal prediction (Yoon et al. 2018). Impacts of the prolonged event included beach erosion as more wave energy reached the coast, minor wave inundation that caused saltwater flooding of lowlying areas, and failed drainage infrastructure due to saltwater blockage (Anderson et al. 2018). The high sea levels were caused by the superposition, or stacking, of multiple contributions (Yoon et al. 2018) that mainly consisted of sea level rise (Chen et al. 2017; Nerem et al. 2018), oceanic mesoscale variability around the Hawaiian Islands (Firing and Merrifield 2004)

Corresponding author: Matthew J. Widlansky, mwidlans@ hawaii.edu
(Fig. 2), and prolonged high regional sea levels about $10 \mathrm{~cm}$ above normal. During August 2017, the Honolulu Harbor tide gauge recorded the highest monthly average water level since records began in $1905(17 \mathrm{~cm}$ above the climatology during 1993-2017). Whereas the amplitude of each process that contributed to the recordhigh sea levels was estimated in near-real time using tide gauge and satellite altimetry measurements (Yoon et al. 2018; see also Table 1), the causes of the largest component of the record event-regionally high sea levels during 2016 and 2017 - are thus far unexplained.

The 2016-17 Hawaii high sea levels followed an El Niño event that peaked during 2015 with the warmest sea surface temperature (SST) anomalies in the equatorial eastern Pacific so far this century (L'Heureux et al. 2017). The SST anomaly in the Niño-3 region during December $2015\left(2.7^{\circ}-2.9^{\circ} \mathrm{C}\right)$ was nearly as warm as during the same month in $1997\left(3.2^{\circ}-3.3^{\circ} \mathrm{C}\right)$, when the strongest El Niño on record peaked (temperature ranges are between different SST reconstructions; Huang et al. 2017; Rayner et al. 2003). Prior to the 

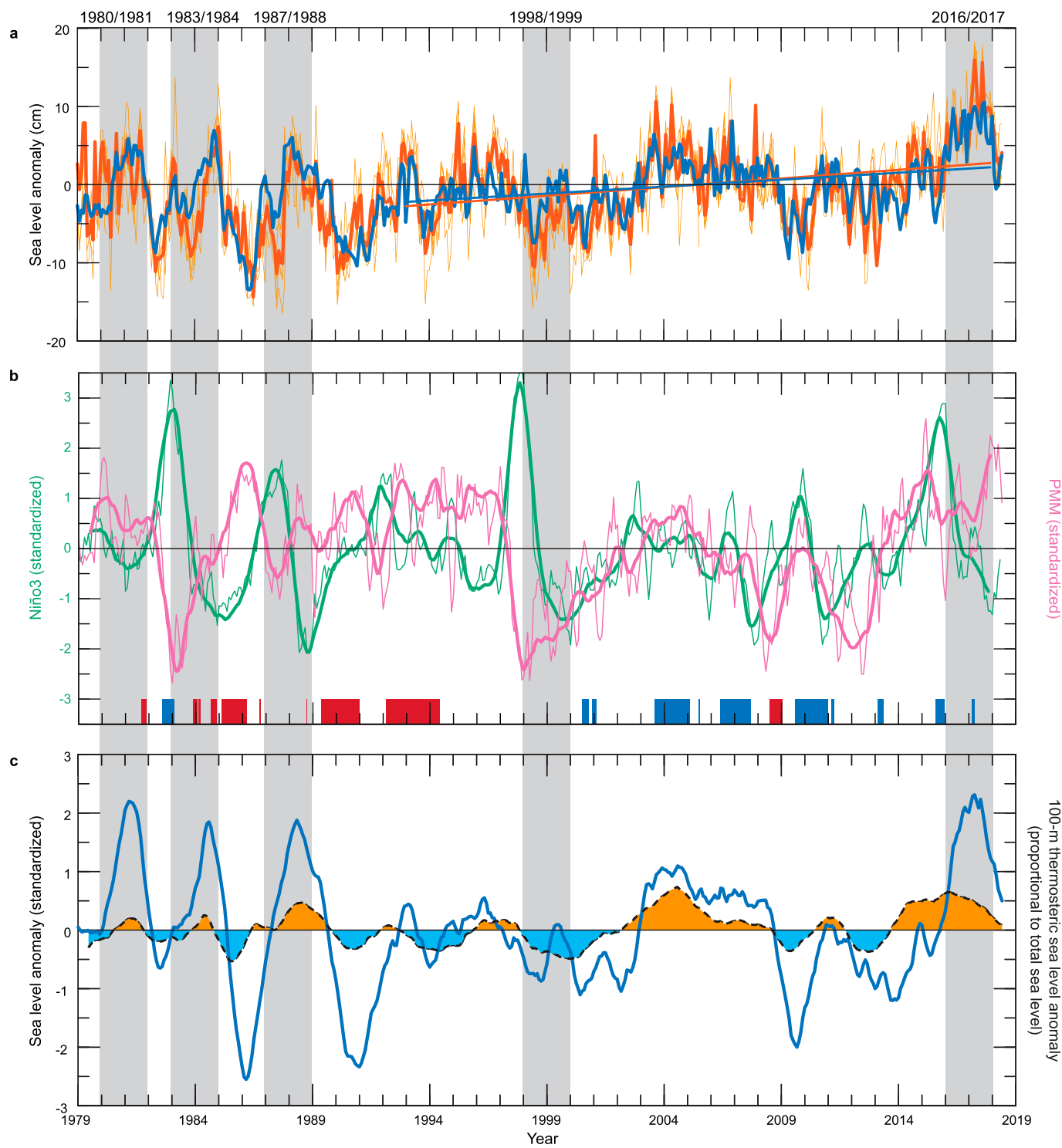

FIG. 1. Observed monthly sea level anomalies around Hawaii and related tropical Pacific climate indices. (a) Five tide gauge records (thin orange), average of tide gauges (thick orange), and merged regional SSH (blue) from ORA-S4 (1979-92) and CMEMS satellite altimetry (1993-Jun 2018). The long-term trends (1993-2017, linear trends) are retained here and removed elsewhere. Locations of the tide gauges and the Hawaii averaging region are shown in Fig. 2. (b) The Niño-3 (green lines), Ekman (red and blue bars indicate the duration of upwelling and downwelling motions exceeding $1 \mathrm{SD}$, respectively), and PMM (purple lines) standardized indices. Thick lines indicate the 13-month running mean of the monthly Niño-3 and PMM indices (thin lines). (c) The SSH anomaly from (a) with a 13-month running mean applied (blue line) and the similarly filtered upper-100-m thermosteric sea level around Hawaii indicated by the dashed lines and respective shading (orange: positive; blue: negative). The SSH anomaly time series is detrended and standardized to have a mean of 0 and SD of 1 . Thermosteric sea level is standardized proportionally to the SD of SSH. Years following El Niño events referred to in the text are shaded gray.

peak of both strong El Niño events [monthly Niño-3 $>2$ standard deviations (SD); Fig. 1b], associated with the warming surface ocean were equatorial Kelvin waves (Wyrtki 1984) that deepened the thermocline in the eastern Pacific and caused a corresponding rise in the sea surface height (SSH; Figs. 3a,b). High sea levels extended from the equator along the Central American and North American coasts due to coastally trapped Kelvin wave propagation (Chelton and Davis 1982). The off-equatorial high SSH was much more 


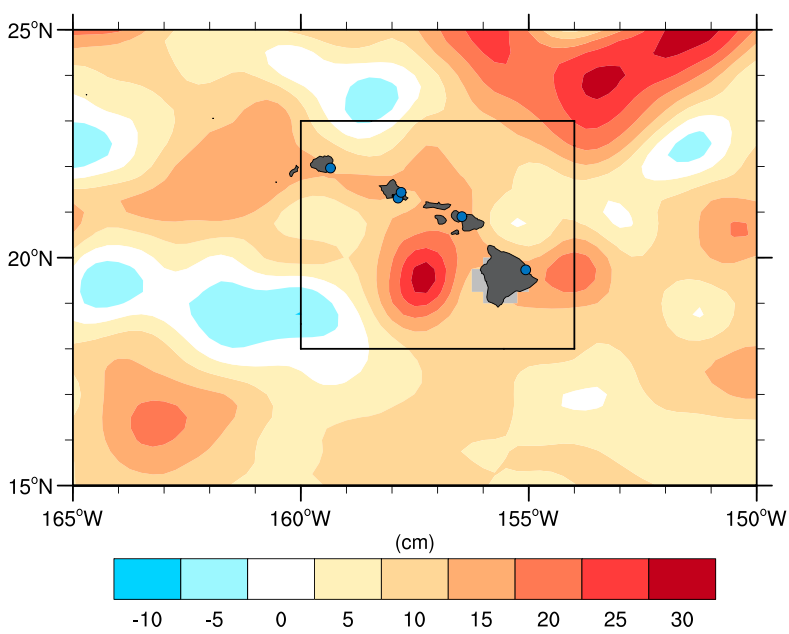

FIG. 2. Satellite observed SSH anomalies $(\mathrm{cm})$ during August 2017. The box indicates the Hawaii averaging region $\left(18^{\circ}-23^{\circ} \mathrm{N}\right.$, $160^{\circ}-154^{\circ} \mathrm{W}$ ), which was $10 \mathrm{~cm}$ above normal and similar to the domain average of the whole map $\left(9 \mathrm{~cm} ; 15^{\circ}-25^{\circ} \mathrm{N}, 165^{\circ}-150^{\circ} \mathrm{W}\right)$. Within the Hawaii region, sea level anomalies ranged from $8 \mathrm{~cm}$ below normal to $30 \mathrm{~cm}$ above normal as a result of, respectively, upwelling and downwelling motions associated with oceanic mesoscale eddies. The long-term trend (1993-2017; see Table 1) is retained here to match the SSH time series in Fig. 1a. Circles indicate locations of the five tide gauges on four of the main Hawaiian Islands (Kauai, Oahu, Maui, and Hawaii from northwest to southeast).

pronounced prior and during the recent strong El Niño compared to the previous event (i.e., 2014/15 vs 1996/97; Fig. 3c). During 2014/15, there was a more prolonged Niño-3 warming (15 months $>0.5 \mathrm{SD}$ compared to 8 months during 1996/97; Fig. 1b); also, anticyclonic wind stress curl offshore the Central American mountain gaps (Alexander et al. 2012) was stronger and broader in area than during 1996/97 (Fig. 3), which likely forced the regional thermocline deeper (Chang et al. 2012). Thus, by the end of 2015, sea levels were much higher in the tropical northeastern Pacific than during 1997 (Fig. 3) although around Hawaii, in the tropical northcentral Pacific, sea levels were slightly below normal throughout both strong El Niño events (i.e., 1997 and 2015; Fig. 1a).

Planetary (Rossby) wave theory suggests that sea level anomalies along the eastern Pacific boundary propagate westward into the basin interior (Jacobs et al. 1994), taking 1-2 years to reach Hawaii based on phase speed estimates from satellite altimetry measurements of sea surface height (SSH) (Chelton and Schlax 1996). This is consistent with the 2016/17 Hawaii high sea level event. By the end of 2016, the Hawaii sea level exceeded +2 SD (Fig. 1c), which was the highest anomaly in over three decades even after accounting for long-term sea level rise. The high sea levels persisted through 2017 and occurred in a broad expanse of the tropical North Pacific between Hawaii and Mexico (Fig. 4a). In contrast, sea levels remained near normal in the same region during 1998/99 after the previous strong El Niño (Figs. 1c and $4 \mathrm{~b})$. This raises the question of which processes determine whether high sea levels follow an El Niño and, more generally, what controls interannual sea level variability around Hawaii.

Large Hawaii sea level swings also occurred during the 1980s (Figs. 1a,c), following El Niño events of weak (1979), strong (1982), or moderate (1986) strength as inferred from the Niño-3 amplitude (Fig. 1b). Since homogeneous satellite altimetry measurements began in 1993, however, the annual mean sea level anomaly around Hawaii exceeded +1 SD only once before 2016/17 (Fig. 1c). That 2003/04 high sea level event was attributed to Pacific decadal variability (Schneider et al. 2002) and associated with a large-scale wind stress curl anomaly that supported a deeper-than-normal thermocline around Hawaii (Firing et al. 2004), rather than with interannual variability associated with El Niño-Southern Oscillation (ENSO). In contrast, the recent high sea levels, which were more than twice as extreme $(>+2 \mathrm{SD}$ vs $+1 \mathrm{SD})$, followed the strongest El Niño since 1997.

There exists somewhat of a mystery concerning Hawaii sea levels, in spite of well-established dynamical understanding of interannual sea level variability in

TABLE 1. Nontidal contributions to the $17.3 \mathrm{~cm}$ monthly sea level anomaly during Aug 2017 at the Honolulu Harbor tide gauge. Hawaii regional amplitudes derived from satellite altimetry measurements are shown in parentheses $(10.3 \mathrm{~cm}$ total monthly anomaly). All anomalies and trends are relative to 1993-2017.

\begin{tabular}{lcc}
\hline \multicolumn{1}{c}{ Process } & Amplitude & Method \\
\hline $\begin{array}{c}\text { Long-term sea level rise } \\
\text { relative to climatology } \\
\text { Regional sea level anomaly }\end{array}$ & $2.8 \mathrm{~cm}(2.2 \mathrm{~cm})$ & $\begin{array}{c}\text { Midpoint of the all-Hawaii tide gauge linear trend in Fig. 1a (midpoint } \\
\text { of satellite altimetry linear trend in Fig. 1a) } \\
\text { Average of the all-Hawaii tide gauge anomaly in Fig. 1a minus the } \\
\text { long-term sea level rise (Hawaii regional-average anomaly in Fig. 2 } \\
\text { minus the long-term sea level rise) } \\
\text { Residual of the Honolulu August 2017 anomaly minus the long-term } \\
\text { sea level rise and the regional sea level anomaly (range of anomalies } \\
\text { within the Hawail region in Fig. 2 minus the long-term sea level rise) }\end{array}$ \\
\hline
\end{tabular}



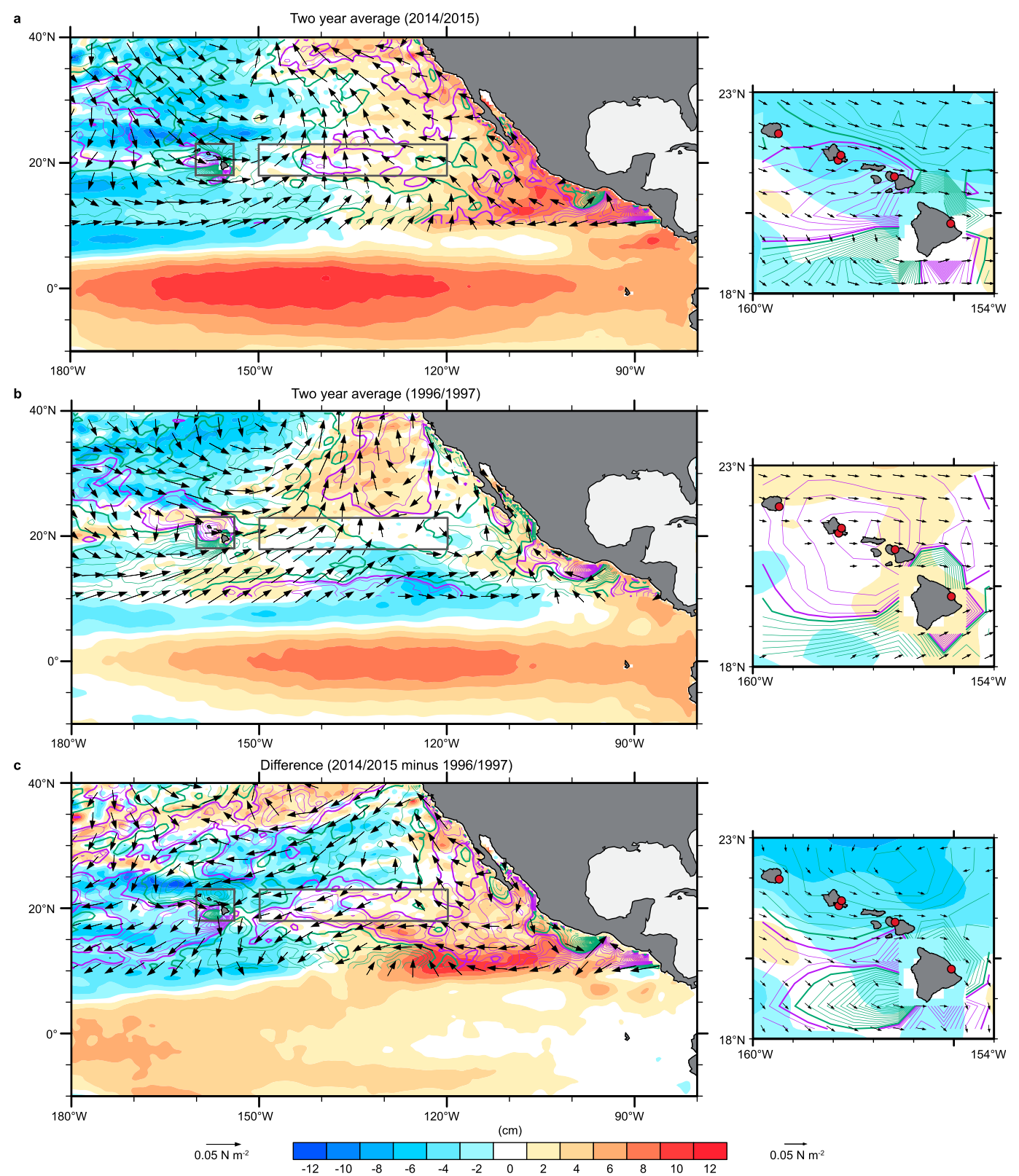

FIG. 3. (left) Satellite-observed SSH (cm; shading), reanalysis wind stress ( $\mathrm{N} \mathrm{m}^{-2}$; vectors), and derived Ekman vertical velocity ( $\mathrm{cm} \mathrm{day}^{-1}$; contours) anomalies before and during the peak of the two strong El Niño events. (a) Jan 2014-Dec 2015, (b) Jan 1996-Dec 1997, and (c) 2014/15 minus 1996/97. Purple and green contours respectively indicate downwelling and upwelling motions, starting at $\pm 1 \mathrm{~cm} \mathrm{day}^{-1}$ with an increment of $\pm 2 \mathrm{~cm} \mathrm{day}^{-1}$. Anomalies are with respect to the 1993-2017 monthly mean climatology. The linear trend (1993-2017) has been removed from each variable at each grid location. The Hawaii and Ekman averaging regions $\left(18^{\circ}-23^{\circ} \mathrm{N}\right.$, $160^{\circ}-154^{\circ} \mathrm{W}$ and $18^{\circ}-23^{\circ} \mathrm{N}, 150^{\circ}-120^{\circ} \mathrm{W}$ ) are indicated by the small and large boxes, respectively. (right) Circles on the regional maps indicate tide gauge locations as in Fig. 2.

most other regions of the tropical Pacific. Dynamical forcing on sea levels include a combination of eastwardpropagating equatorial Kelvin waves (Wyrtki 1984), coastal-trapped Kelvin waves (Chelton and Davis 1982), and westward-propagating Rossby waves (Chelton and Schlax 1996), which deepen or shoal the thermocline while the SSH generally mirrors the subsurface changes (Delcroix 1998). Oceanic models of the Kelvin and Rossby wave theory describe well these processes and, specifically, the sea level response to winds associated with strong El Niño events (e.g., Widlansky et al. 2014, 2015). The dynamical models are particularly successful 


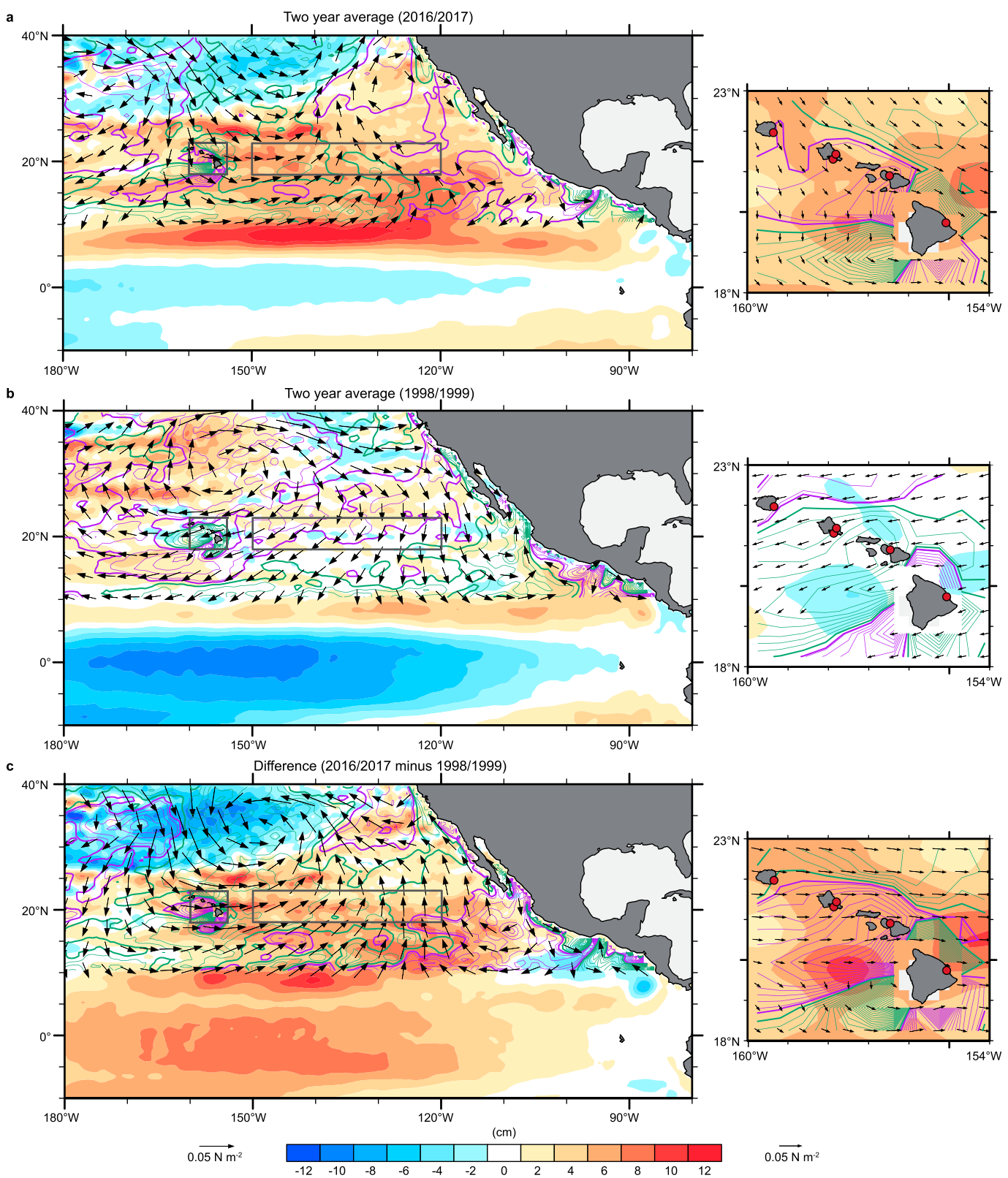

FIG. 4. As in Fig. 3, but for anomalies after the peak of the two strong El Niño events. (a) Jan 2016-Dec 2017, (b) Jan 1998-Dec 1999, and (c) 2016/17 minus 1998/99.

in the equatorial Pacific and near the eastern boundary of the ocean (e.g., McGregor et al. 2012), but inconsistently resolve the sea level variability around Hawaii (Fu and Qiu 2002). Such a deficiency suggests that other modes of variability, or perhaps thermodynamical processes, may be involved. Around Hawaii, oceanic temperature variations near the surface are in fact correlated with interannual sea level anomalies (Fig. 1c; $r=0.61$ ), with the upper $100 \mathrm{~m}$ of the ocean having been especially warm during the high sea levels of 2016/17 and also 2003/04 (i.e., positive thermosteric contributions to sea level anomalies during both times) but cooler than normal during 1998/99 when sea levels were near normal. Yet, the question remains about how the temperature variations around Hawaii are related to large-scale forcing and modes of variability.

Understanding why the sea level at Hawaii remained near normal after the strongest El Niño in 1997, whereas record-high sea levels occurred following the $2015 \mathrm{El}$ Niño, is key to better explaining the sea level and thereby the ocean heat content relationship with ENSO throughout the eastern half of the tropical North Pacific 
(i.e., the SSH difference in Fig. 4c). For Hawaii, better understanding of the sea level response to El Niño may help to improve future regional outlooks of interannual variability and associated coastal flooding hazards. More broadly, it is unknown why after some El Niño events, sea level anomalies traverse the basin, whereas other times oceanic anomalies are confined to the eastern boundary.

The paper is organized as follows. First, through observational analysis (section 2), we describe the oceanatmosphere climate processes related to interannual sea level variability in the tropical northeastern and north central Pacific with a focus around Hawaii. In particular, we identify differences in atmospheric forcing that could potentially explain the Hawaiian sea level anomalies (near-normal vs record-high) following the 1997 and 2015 El Niño events. Next, we utilize a hierarchy of increasingly sophisticated models (section 3) to explore how each of these processes contributed to sea level variability and identify conditions that led to the 2016/17 high sea level event. We then assess in coupled oceanatmosphere climate model projections (section 4) the likelihood of such conditions occurring in the remainder of the twenty-first century with greenhouse warming. Finally, we discuss in section 5 the implications of these results with regards to oceanic teleconnections and coastal impacts of sea level variability.

\section{Observational analysis}

\section{a. Data}

To describe the sea level around Hawaii (Fig. 1a) we used measurements from shore-based tide gauges and satellite-based altimetry, which were complemented by an ocean model reanalysis of the SSH. Five tide gauge records (Hilo, Honolulu, Kahulai, Mokuoloe, and Nawiliwilli) covering the January 1979-June 2018 period on four of the main Hawaiian Islands (Fig. 2) were used from the Quality Assessment of Sea Level Data archive (Caldwell et al. 2015). We reprocessed daily gridded altimetry data $\left(0.25^{\circ}\right.$ latitude $\times$ longitude $)$ from the SSALTO/DUACS multimission dataset distributed by the European Copernicus Marine Environment Monitoring Service (CMEMS) into monthly anomalies (January 1993-June 2018) with the dynamic atmospheric correction removed so that the inverse-barometer effect on sea level was included in our analysis. We note that the altimetry product is not affected by any vertical land motion in Hawaii. Both the altimetry and tide gauge data do include effects of self-attraction and loading associated with the global hydrological cycle (Tamisiea et al. 2010; Vinogradova et al. 2010), although the variability associated with this is small in the Hawaii region (i.e., around $1 \mathrm{~cm}$ or less). Most importantly for assessing large-scale (i.e., tropical northeastern and north-central Pacific) and regional (i.e., Hawaii) processes, satellite altimetry describes the sea level variability away from the tide gauges. We used simulated monthly mean SSH from the ECMWF Ocean Reanalysis System 4 (ORA-S4; Balmaseda et al. 2013) as a proxy for large-scale and regional sea level variability prior to the satellite altimetry observations (1979-92), with the inverse-barometer effect added to the original ORA-S4 SSH variable. The simulated SSH from ORA-S4 averaged around Hawaii is similar to the average tide gauge monthly anomalies except for notable deviations during 1979-81 (Fig. 1a), which was prior to the assimilation of satellite-measured SST (Reynolds et al. 2002) into the ocean reanalysis.

We used atmosphere (ERA-Interim; Dee et al. 2011) and ocean reanalysis (ORA-S4) products to assess dynamical and thermodynamical air-sea coupling processes affecting Hawaii sea level. We calculated the Ekman pumping velocity as

$$
w_{E}=\nabla \times \frac{\tau}{\rho f},
$$

where $\tau$ is the surface wind stress, $\rho$ is the representative seawater density $\left(1030 \mathrm{~kg} \mathrm{~m}^{-3}\right)$, and $f$ is the Coriolis parameter. We used the $17^{\circ} \mathrm{C}$ isotherm of potential temperature as a proxy for the thermocline depth as it is indicative of the average maximum vertical temperature gradient near Hawaii (Fiedler 2010). The results are robust to using a range of isotherms between $15^{\circ}$ and $20^{\circ} \mathrm{C}$. We considered surface wind speed as a proxy for the amount of cooling from the ocean mixed layer via surface heat fluxes (McPhaden and Hayes 1991; Meyers et al. 1986), omitting the effects of any changes in the air-sea humidity or temperature gradients (Lin et al. 2008). Objectively analyzed latent and sensible heat fluxes are from the Woods Hole Oceanographic Institution OAFlux project (Yu and Weller 2007), which together mirrors the wind speed.

For all variables, we calculated the monthly mean anomalies with respect to the 1993-2017 average seasonal cycle. We also subtracted the location-specific linear trend for the same period; thus, the contribution of recent sea level rise (Fig. 1a) is removed from our assessment of the 2017 high sea level event (Fig. 1c and Table 1).

\section{b. Description}

Satellite altimetry shows the higher-than-normal sea levels at the Mexican coast during 1997 and 2014-15, with evidence of westward propagation toward Hawaii (Figs. 5a,b), which is consistent with the canonical sea 
level response after the peak of El Niño (Fig. 6a). The high eastern Pacific sea level during 2014 was associated with weak El Niño conditions (McPhaden et al. 2015; Menkes et al. 2014) that occurred prior to the strong El Niño in 2015. The sea level at Hawaii rose during 2016 and reached a record high during 2017, but only small-amplitude anomalies occurred during 1998 and 1999 (Fig. 1c). In both cases, higher sea levels coincided with a deepening of the thermocline around Hawaii (Figs. 5c,d). This is dynamically consistent with westward-propagating oceanic Rossby waves (Chelton and Schlax 1996; Jacobs et al. 1994; Qiu et al. 1997) that originated during the preceding El Niño conditions, likely due to a combination of coastal-trapped Kelvin wave energy radiating offshore (Hughes et al. 2019; Johnson and O'Brien 1990) and downwelling, or Ekman pumping (Timmermann et al. 2010), associated with anticyclonic wind stress curl within the basin ( $\mathrm{Fu}$ and Qiu 2002).

A possible explanation for the different Hawaii sea level anomalies following the El Niño events is that anomalous wind stress curl forcing acted to enhance or diminish the Rossby wave amplitudes en route to Hawaii. More anticyclonic wind stress curl occurred during 2014/15 near the Mexican and Central American coasts compared to $1996 / 97$ (Fig. 3c), which may have enhanced the Rossby waves initially as they propagated away from the coast. After the peak of both El Niño events, however, there were only subtle differences in the wind stress curl between Mexico and Hawaii (slightly more anticyclonic during 1998/99; Fig. 4b), which suggests that large-scale Ekman pumping does not account for the different sea level anomalies at Hawaii. Although to the lee of the Hawaiian Islands, near the wind wake caused by the high mountains (Xie et al. 2001), there were substantial Ekman pumping differences after the two strong El Niño events (Fig. 4, insets), which could have contributed to mesoscale sea level variability (Fig. 2) or other downstream effects. Prior to the two El Niño events, there were more subtle differences in the Ekman pumping around Hawaii as the trade winds were weaker than normal in both cases (Fig. 3, insets).

Rather than wind stress curl, one of the most striking differences in the tropical northeastern Pacific atmosphere following the $2015 \mathrm{El} \mathrm{Niño} \mathrm{was} \mathrm{that} \mathrm{the} \mathrm{trade}$ winds remained weak for long after El Niño ended (i.e., southwesterly anomalies opposing the typical northeasterly wind between Hawaii and Mexico during 2016/17; Fig. 4a), whereas the winds were mostly stronger than normal during 1998/99 (Fig. 4b). The difference in winds following the two El Niño events (Fig. 4c) closely resembles the wind stress pattern associated with the Pacific meridional mode (PMM; cf. Fig. 6b; Chiang and Vimont 2004), which has been positive almost every month since 2015 but was extremely negative during 1998/99 (Fig. 1b).

The weaker winds during 2016/17 presumably reduced the surface cooling of the ocean mixed layer upstream of Hawaii (Figs. 7a,b; nominally, the upper $100 \mathrm{~m}$ ) and, thus, the effect on upper-ocean thermosteric sea level was positive (Fig. 1c), as is typical when the PMM is positive (Fig. 6b). During 1998/99, nearly the opposite pattern was observed (i.e., decreased thermosteric sea level associated with higher wind speeds and enhanced surface cooling; Figs. 1c and 7c,d). After both El Niño events, a westward propagating deepening of the thermocline (Figs. $7 \mathrm{~b}, \mathrm{~d}$ ) was underlying the mixed layer temperature anomalies, indicative of Rossby wave propagation (i.e., the oceanic dynamical response to ENSO).

\section{Model hierarchy}

Here, using three models with varying complexities, we test the hypothesis that the weak trade winds associated with the positive PMM during 2016/17 contributed to the record-high sea level. We also test an alternative hypothesis that the weak El Niño and enhanced Ekman pumping near the Central American coast that preceded the 2015 El Niño (the 1997 El Niño had no such precursor) account for the high sea levels that Hawaii experienced in 2017. The hypotheses are tested in a hierarchical modeling framework consisting of a linear regression model of the Hawaii sea level response to large-scale climate indices, a shallow-water model that only resolves ocean dynamics forced by surface wind stress, and an ocean general circulation model (OGCM) with prescribed surface flux forcing that resolves dynamical and thermodynamical processes.

\section{a. Linear regression model}

We first described the interannual sea level variability around Hawaii with a multiple linear regression model that represents the additive contributions from the ENSO and PMM climate modes as well as Ekman pumping velocity averaged upstream of Hawaii $\left(18^{\circ}-23^{\circ} \mathrm{N}, 150^{\circ}-120^{\circ} \mathrm{W}\right)$. We used monthly Hadley Centre SST (Rayner et al. 2003) from the Niño-3 region $\left(5^{\circ} \mathrm{S}-5^{\circ} \mathrm{N}, 150^{\circ}-90^{\circ} \mathrm{W}\right)$ as an index of $\mathrm{El}$ Niño variability and, more generally, as a proxy for a deep thermocline and high sea level in the tropical eastern Pacific (Wyrtki 1984). The PMM index (Chiang and Vimont 2004), which is calculated independently of ENSO, describes the interannual-decadal coupled variability of SST and 10-m winds in the region 
Sea levels before, during, and after the 2015 strong El Niño

a

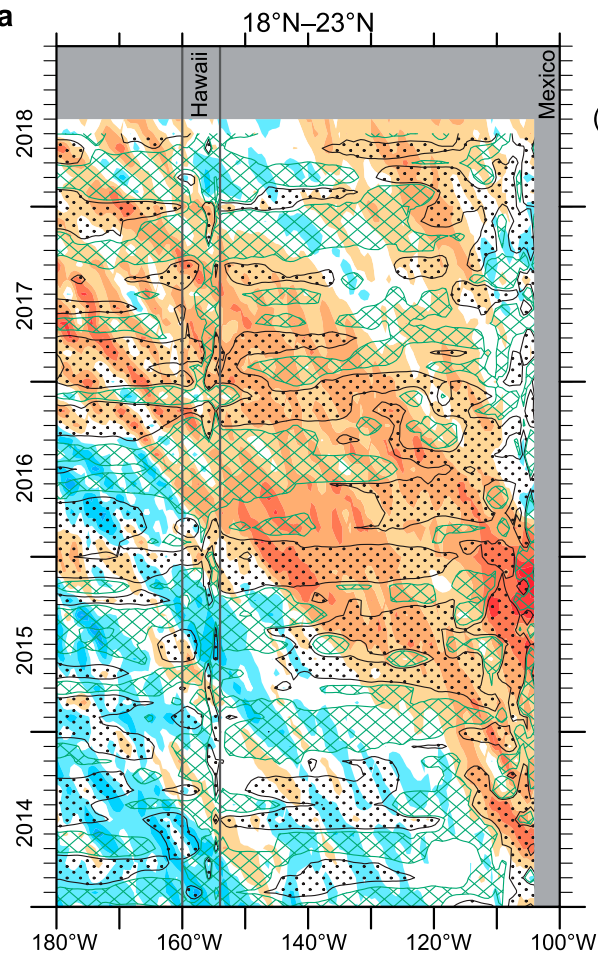

c $(\mathrm{cm})$

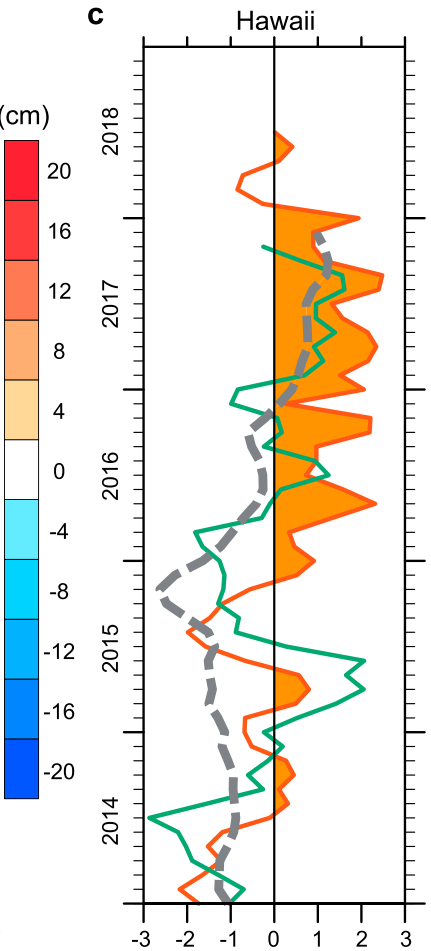

Sea levels before, during, and after the 1997 strong El Niño

b

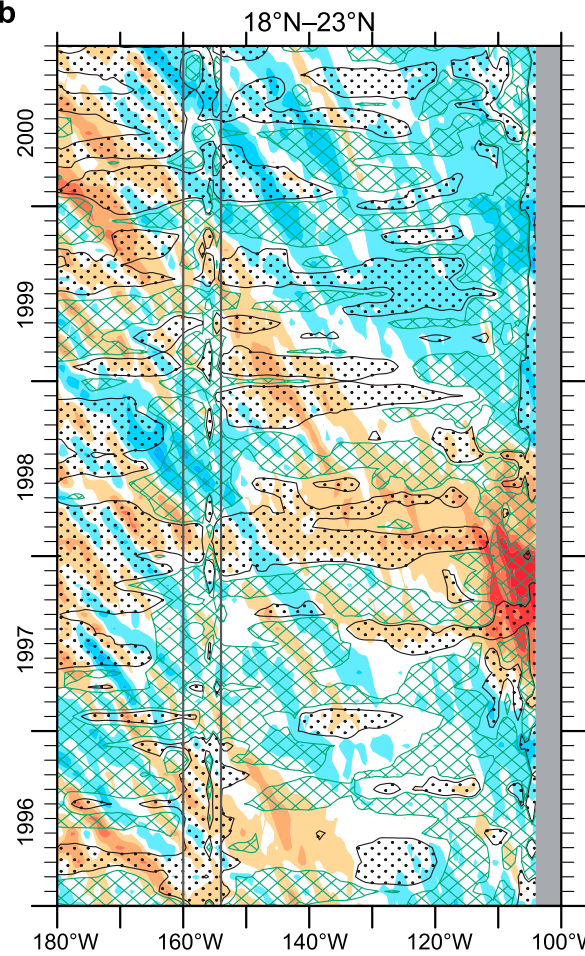

d

d

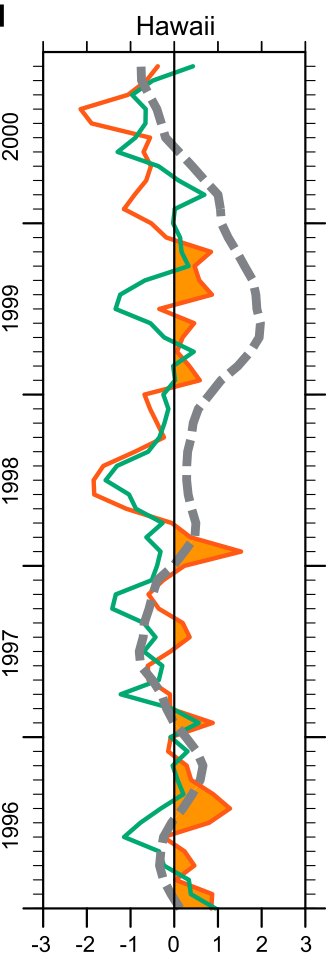

FIG. 5. Observed oceanic and atmospheric conditions related to Hawaii sea level before, during, and after the two strong El Niño events. (a),(b) Time vs longitude anomalies of satellite-observed SSH (shading) and reanalysis-derived Ekman vertical velocity (green hatching: upwelling; black dots: downwelling; absolute 

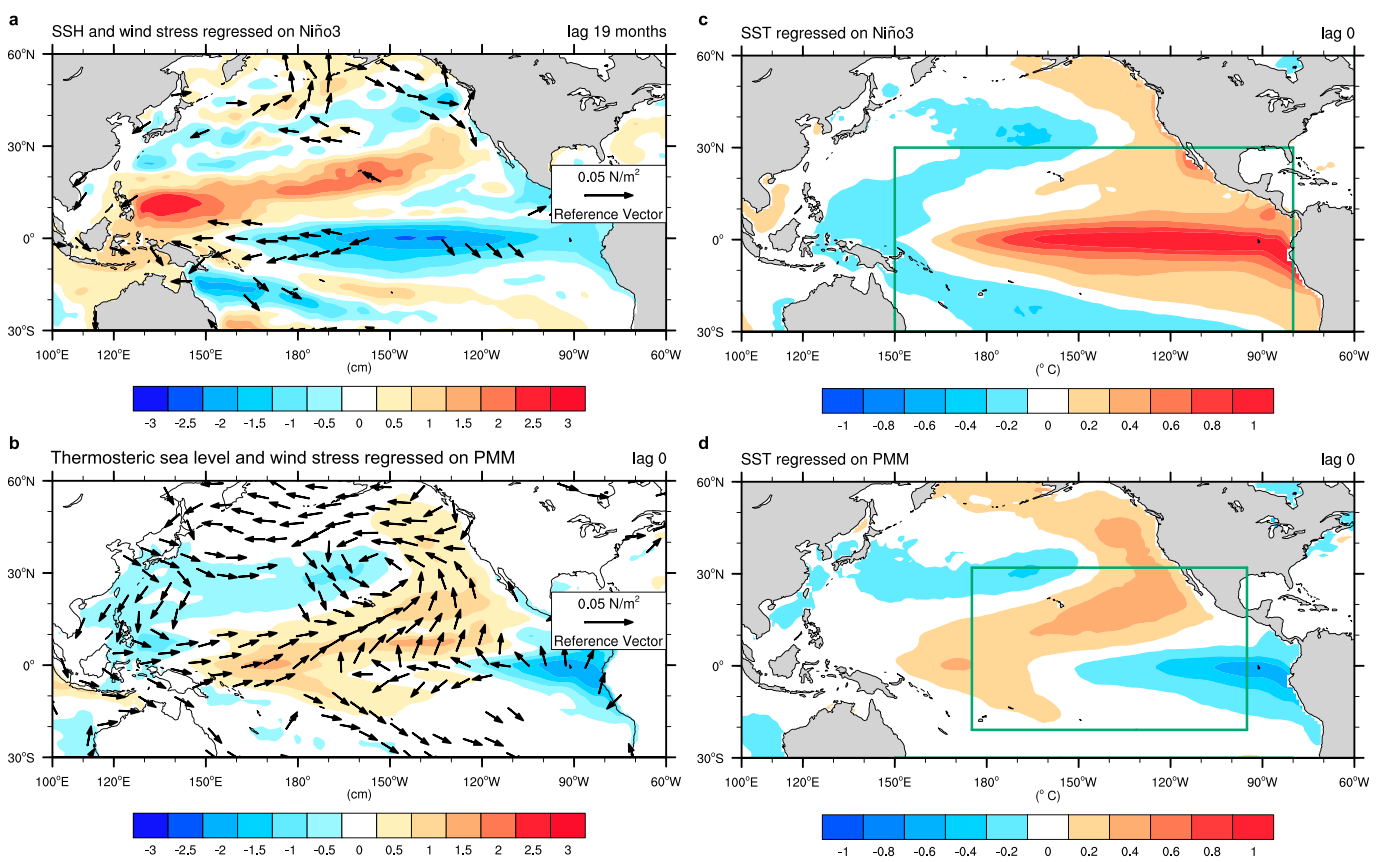

FIG. 6. Observed sea level, wind stress, and SST regression patterns associated with the Niño-3 and PMM indices. (a),(b) Regression of SSH and wind stress onto the Niño-3 and PMM indices (lag 19 and 0 months, respectively). For the PMM regression, the upper-100-m thermosteric sea level is shown. (c),(d) Regression of SST onto the Niño-3 and PMM indices (lag 0 months), respectively. The SST patterns within the boxes $\left[30^{\circ} \mathrm{S}-30^{\circ} \mathrm{N}, 150^{\circ} \mathrm{E}-80^{\circ} \mathrm{W}\right.$ in (c) and $21^{\circ} \mathrm{S}-32^{\circ} \mathrm{N}, 175^{\circ} \mathrm{E}-95^{\circ} \mathrm{W}$ in (d)] are used to project the future change of the corresponding Niño-3 and PMM indices, respectively.

$21^{\circ} \mathrm{S}-32^{\circ} \mathrm{N}, 175^{\circ} \mathrm{E}-95^{\circ} \mathrm{W}$. The $\mathrm{PMM}$ is indicative of the trade wind strength (Fig. 6b) and, thereby, the atmosphere-ocean thermodynamical coupling strength (i.e., sensible and latent heat fluxes increase with wind speed), especially in the tropical North Pacific between Hawaii and Mexico (Chiang and Vimont 2004).

Using the detrended Hawaii sea level anomaly, Niño-3, Ekman, and PMM monthly indices, we first smoothed each anomaly time series using a 13-point running mean to isolate the interannual variability (Figs. 1b,c). Next, we standardized the indices to have a mean of 0 and SD of 1, which we used as the predictand (Hawaii sea level) and predictors (Niño-3, Ekman, and PMM) in the regression model. When wind speeds are low (e.g., during positive PMM), there is reduced surface cooling (e.g., Fig. 7a) but that thermodynamical effect on sea level is diminished if there is also strong upwelling of cooler and denser subsurface water (i.e., Ekman suction). Thus, we switched off the PMM predictor when the Ekman index is greater than $1 \mathrm{SD}$ (indicated in Fig. 1b). A sensitivity test to the choice of Ekman suction threshold revealed $1 \mathrm{SD}$ to provide relatively high correlation between the PMM index and the upper-ocean thermosteric sea level at Hawaii, while still retaining most of the degrees of freedom associated with comparison of the full time series.

We calculated the lead-lag correlation coefficients $r$ between each pair of indices during 1981-2017 (Fig. 8), which includes the recent high sea level event because it is unique in the observational record. Niño-3 typically

values $>2 \times 10^{-7} \mathrm{~m} \mathrm{~s}^{-1}$ are shown) during 2014-June 2018 and 1996-2000, respectively. Latitudinal averaging for the cross sections is between $18^{\circ}$ and $23^{\circ} \mathrm{N}$. The longitude range of the main Hawaiian Islands $\left(160^{\circ}-154^{\circ} \mathrm{W}\right)$ is enclosed by the vertical lines. The Mexican coast is gray. (c),(d) Standardized time series of the Hawaii sea level anomaly (orange; positive is shaded), reanalysis thermocline depth (green; inferred from the $17^{\circ} \mathrm{C}$ potential temperature isotherm), and simulated thermocline depth from the shallow-water model (dashed gray). Anomalies are with respect to the 1993-2017 monthly mean climatology. The linear trend (1993-2017) has been removed from each variable at each grid location. 


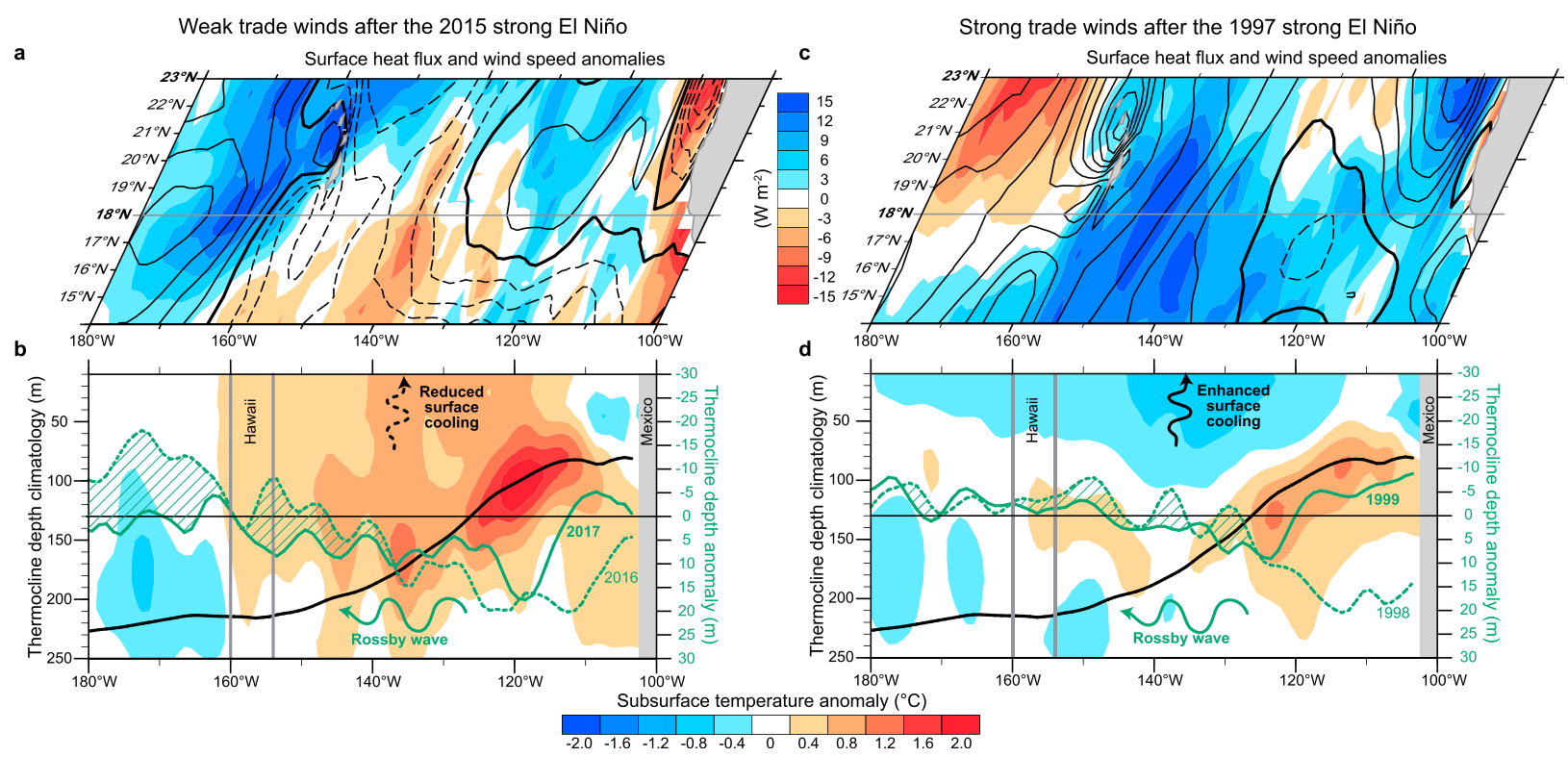

FIG. 7. Observed oceanic and atmospheric conditions related to Hawaii sea level after the two strong El Niño events when the PMM is either (left) positive (weak trade winds) or (right) negative (strong trade winds). (a),(c) Anomalies during 2016/17 or 1998/99 of latent and sensible heat flux ( $\mathrm{W} \mathrm{m}^{-2}$; shading; positive is more flux out of the ocean) and wind speed (contour interval: $0.1 \mathrm{~m} \mathrm{~s}^{-1}$; dashed: negative; solid: positive). (b),(d) Ocean potential temperature anomalies ( ${ }^{\circ} \mathrm{C}$; shading) during 2016/17 or 1998/99. Thermocline depths are indicated (black: climatology, left axes; green-dashed and green-solid: anomalies during 2016 or 1998 and 2017 or 1999, right axes). Hatching indicates where the 2017 or 1999 thermocline is deeper than during 2016 or 1998, respectively. The dashed (solid) vertical arrows illustrate reduced (enhanced) surface cooling related to the wind speed anomalies in (a) and (c). The horizontal arrows illustrate westwardpropagating Rossby wave energy associated with the deepening thermocline in (b) and (d). Latitudinal averaging for the cross sections is between $18^{\circ}$ and $23^{\circ} \mathrm{N}$ in (b) and (d). Anomalies are with respect to the 1993-2017 monthly mean climatology. The linear trend (1993-2017) has been removed from each variable at each grid location.

leads Hawaii sea level by 19 months $(r=0.63)$, whereas the PMM and sea level only have a weak correlation that is not statistically significant between 0 - and 24-month lead (by 32-month lead, the PMM is correlated with Hawaii sea level at $r=0.44$; however, that may be related to the PMM also leading Niño-3 by 16 months at $r=0.47)$. There is a much stronger correlation between PMM and the upper-100-m ocean temperature around Hawaii (i.e., the thermosteric sea level anomaly; Fig. 1c), which peaks at 8-month lead ( $r=0.46$ for the full time series and $r=0.67$ if omitting times of large Ekman suction). The Ekman index leads Hawaii sea level by 10 months $(r=-0.39)$. All correlations are significant at the $95 \%$ confidence level, unless otherwise indicated. For each pair of time series, we determined the critical value for $r$ based on the higher of the two autocorrelation decay time scales, which determines the effective sample size and, thus, the critical $t$ score (Wilks 2006). Between 0- and 19-month lead, there are only weak (nonsignificant) correlations between Niño-3 and PMM as well as between Niño-3 and Ekman, which suggests that the indices vary mostly independently. Thus, we lag the predictors in the regression model by either 19 months (Niño-3), 10 months (Ekman), or 8 months
(PMM). The regression coefficients are, respectively, $0.59,-0.35$, and 0.36 for the Niño-3, Ekman, and PMM indices.

The multiple linear regression model explains $59 \%$ of the Hawaii sea level interannual variability (i.e., the square of the $r$ value listed in the Fig. 9 caption), which is a stronger correlation than using only the Niño-3 index, or just the Niño-3 and Ekman indices without PMM, as predictors. The regression model with all predictors included describes well the evolution from near normal to extremely high sea level $(>2$ SD) during 2015-17; however, the predicted sea level rise during 1997-99 is larger than observed (Fig. 9c), although the bias is smaller compared to the other regression models (Figs. 9a,b). Most importantly, the regression model including PMM as a predictor is the only one to predict the highest sea level during 2017 instead of 1999.

To describe the uncertainty of the multiple regression model of how Hawaii sea level varies as a function of Niño-3, Ekman, and PMM indices, we estimated the $90 \%$ confidence interval (Wilks 2006) around the regression function (Fig. 9). Considering the large sample size (37 years of monthly model residuals), we assumed that the mean square error (MSE) of the prediction is 

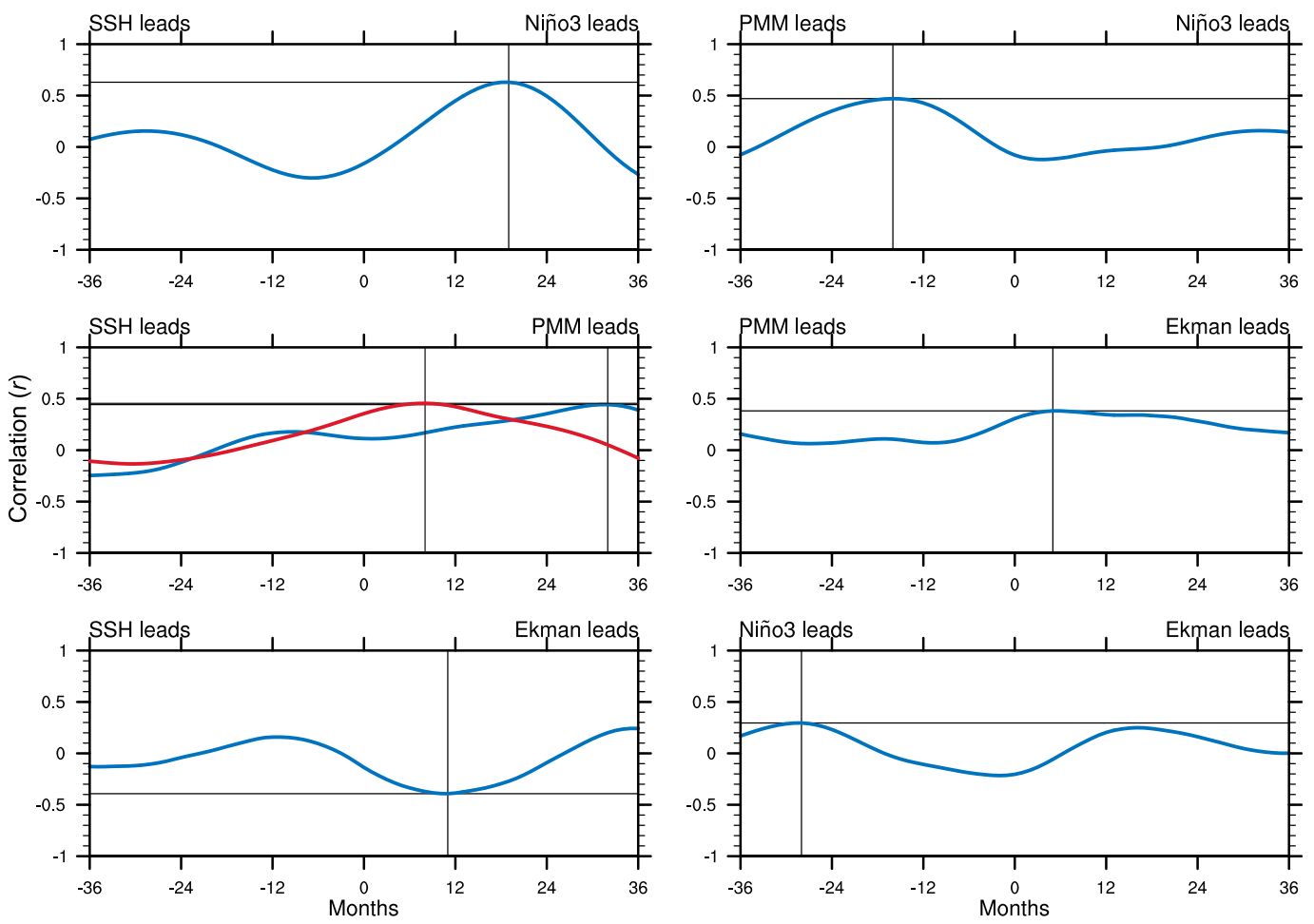

FIG. 8. The lead-lag correlation between the Hawaii sea level anomaly and each of the predictor indices used in the multiple linear regression model. Correlations between pairs of predictor indices are also shown. For the PMM predictor, the correlation with the upper-100-m thermosteric sea level is compared (red). The vertical lines indicate the lead or lag month of maximum $r$ (horizontal lines). After applying a 13-month running mean, all the time series (1979-2017) are detrended and standardized to have a mean of 0 and SD of 1.

similar to the prediction variance (i.e., negligible sampling variations) and, thus, that the confidence interval is proportional to the MSE multiplied by the $Z$ score associated with $90 \%$ of values (1.645). Furthermore, we measured the prediction performance with models of varying predictors set to zero and found the highest explained variance when all three indices were used (Fig. 9c).

The linear regression model of Hawaii sea level onto the combined effects of ENSO, Ekman dynamics, and the PMM explains most of the interannual variability (Fig. 9c). By including information about the PMM (i.e., trade wind speed and the associated surface warming or cooling around Hawaii), we better describe the Hawaii sea level variability compared to a regression model based only on ENSO and Ekman dynamics, especially following the 1997 and 2015 El Niño events, which suggests that thermodynamics (i.e., the effects of surface heat fluxes on mixed layer density, which on annual and longer time scales can also penetrate into the upper thermocline) are important.

\section{b. Shallow-water model}

We next attempted to simulate the Hawaii sea level variability as a function of Rossby wave propagation (i.e., without any thermodynamic forcing) in a dynamical model that resolves the thermocline response to surface wind stress forcing. We used a 1.5-layer reducedgravity shallow-water model of the stratified ocean with $1^{\circ}$ horizontal resolution (McGregor et al. 2007). The gravity wave speed, and hence also the Rossby wave phase speed, is prescribed by imposing the observed Rossby radius of deformation (Chelton and Schlax 1996). Anomalous wind stresses from the ERA-Interim drive motion in the top layer of the model during 19792017, while the bottom layer is assumed motionless and infinitely deep. We measured the vertical displacements of the thermocline, which in the model is the interface between the top and bottom layers, to infer changes in sea level.

Whereas this shallow-water model has demonstrated utility in resolving thermocline variability in the equatorial Pacific (McGregor et al. 2007), as well as the sea level in parts of the tropical South Pacific (Widlansky et al. 2014), we had only moderate success recreating the Hawaii sea level (Figs. 5c,d and 10; 33\% variance explained of 1979-2017 monthly observations). Furthermore, the simple linear regression model better describes Hawaii sea level variability than this shallow-water model, at least 


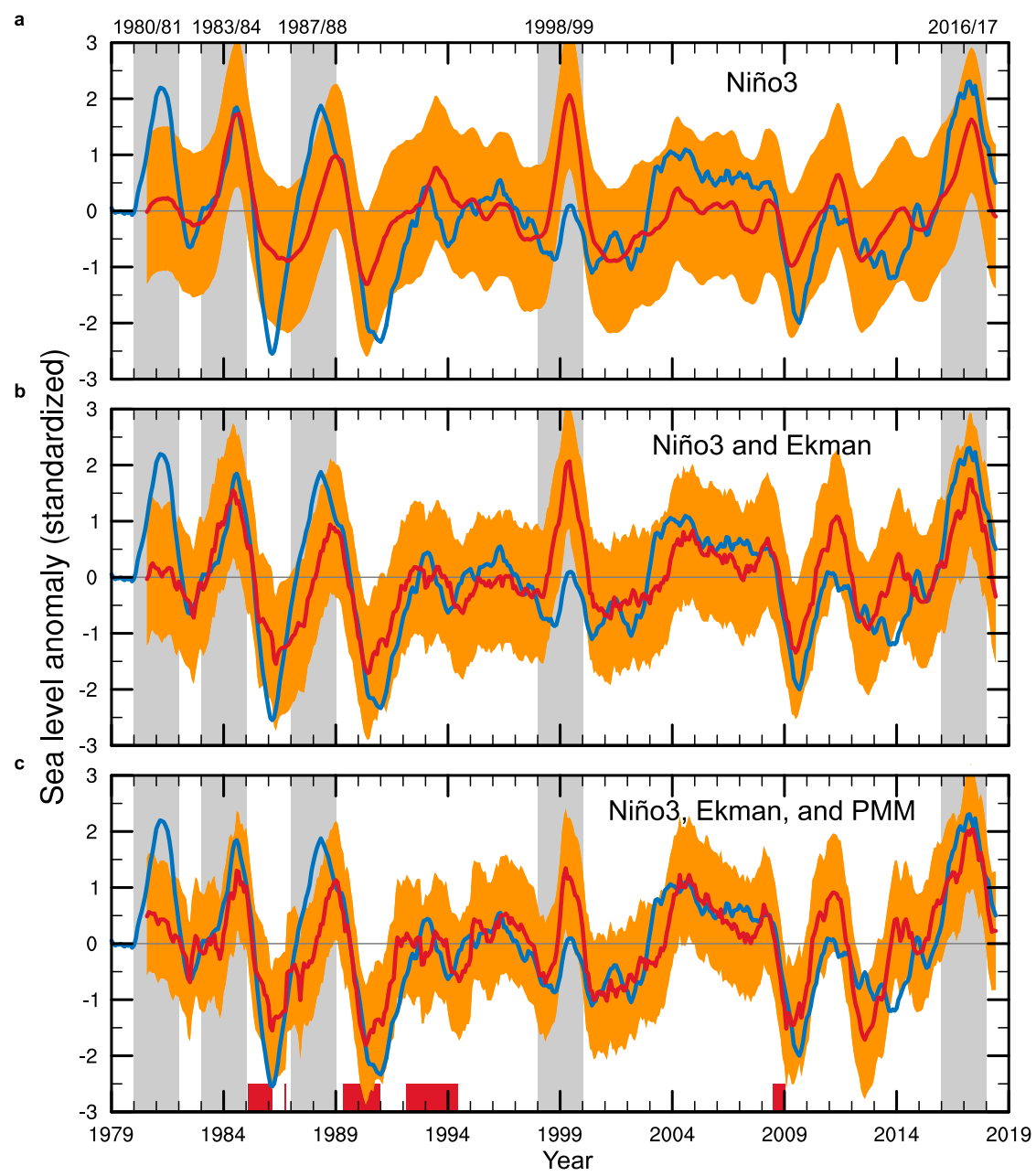

FIG. 9. The Hawaii sea level anomaly (13-month running mean of regional SSH as in Fig. 1c; blue) reconstructed using a linear regression model (red) with various combinations of predictors, showing (a) only Niño-3 (19-month lead; $r=0.63$ ), (b) Niño-3 plus Ekman (10-month lead; $r=0.70$ ), and (c) Niño-3, Ekman, and PMM (8-month lead; $r=0.77$ ) smoothed indices as predictors. Orange shading encloses the $90 \%$ confidence interval. The time series are detrended and standardized to have a mean of 0 and SD of 1 . Years following El Niño events referred to in the text are shaded gray. Red bars in (c) indicate times when the PMM index is not used as a predictor (i.e., Ekman suction greater than $1 \mathrm{SD}$ ).

at annual and longer time scales ( $61 \%$ vs $37 \%$ variance explained). The relatively worse performance of the shallow-water model is despite having tuned the prescribed observed gravity wave phase speed (Chelton and Schlax 1996) (multiplied by $125 \%$ ) to achieve the highest possible local correlation and realistic westward propagating anomalies (Fig. 11). During the two years following both the 1997 and 2015 strong El Niño events, the shallow-water model simulates a deepening of the thermocline around Hawaii (i.e., inferred higher SSH; Fig. 11); however, the simulated change was much larger than observed during 1999 (Fig. 5d) and somewhat too small during 2017 (Fig. 5c). Rerunning the shallow-water model with wind stresses from the
JRA-55 (Kobayashi et al. 2015) produced similar results ( $r$ difference was less than 0.1).

\section{c. $O G C M$}

\section{1) EXPERIMENTAL DESIGN}

To explore the dynamical as well as thermodynamical forcing on Hawaii sea level variability in a general circulation model framework, we used the NCAR Community Earth System Model, version 1.1.2, and specifically its ocean model component, the Parallel Ocean Program version 2 (POP2; Smith et al. 2010), which we ran at a nominal $1^{\circ}$ horizontal resolution. The POP2 OCGM has been shown to fully resolve the 


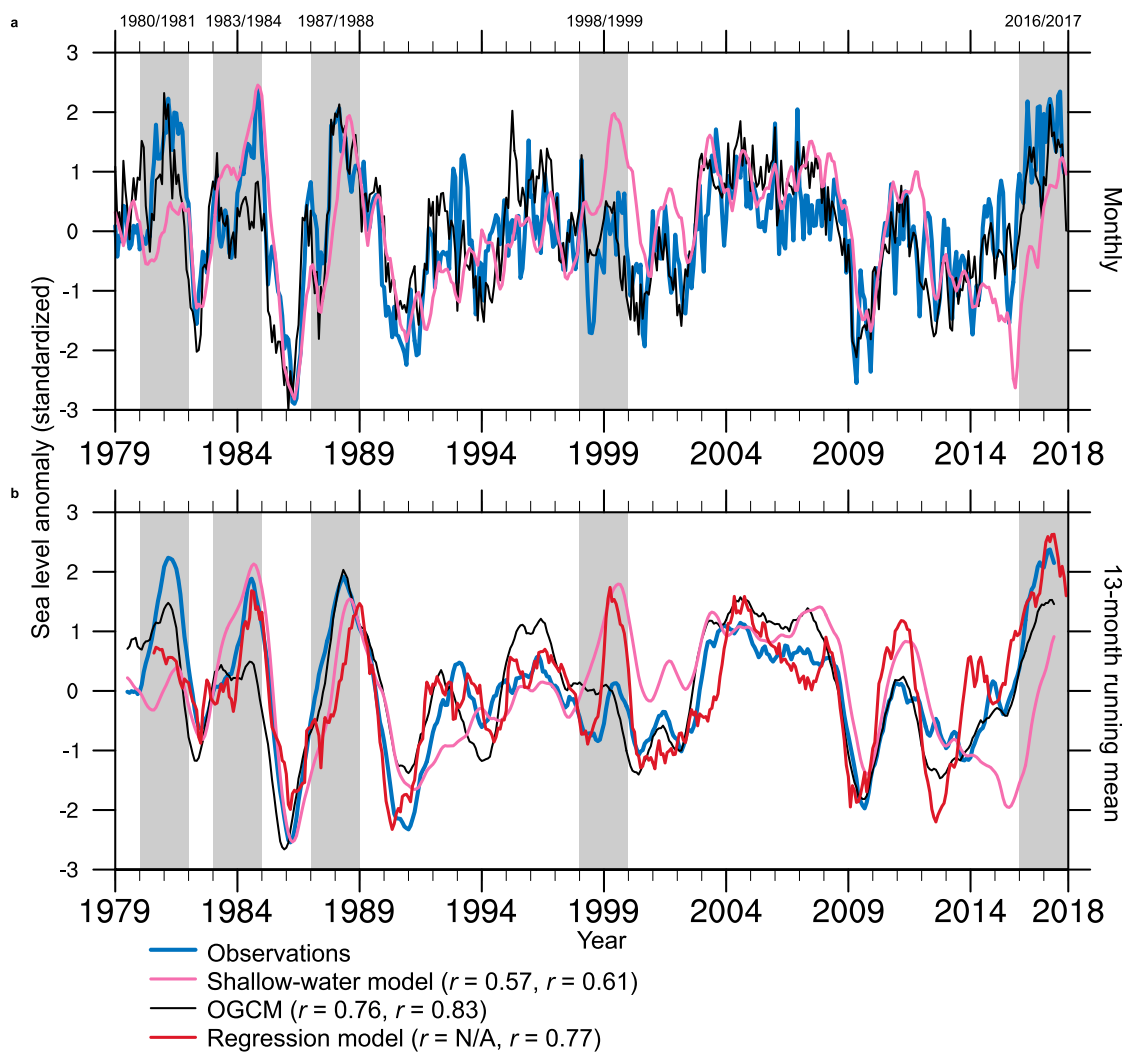

FIG. 10. Observed and simulated sea level anomalies around Hawaii (box in Fig. 2) on (a) monthly and (b) interannual time scales. Shown are SSH anomalies from the observations, multiple linear regression model [in (b) only], shallow-water model, and the OGCM control simulation. Anomalies for each product have been standardized so that the temporal SD is 1 . Prior to standardization, the SDs of the observations and OGCM monthly time series are 3.9 and $2.8 \mathrm{~cm}$, respectively. Not listed are SDs of the regression model, which is calculated using standardized predictors, and the shallow-water model, whose variability is computed from thermocline depth anomalies (SDs have different units than SSH). Standardized anomalies are with respect to the 1993-2017 monthly mean climatology and the linear trend (1979-2017) has been removed. Years following El Niño events referred to in the text are shaded gray.

large-scale ocean dynamics and thermodynamics associated with interannual sea level variability in the tropical Pacific (Fasullo and Gent 2017), although the self-attraction and loading effect is not resolved as is the case for all current-generation models of this type (Tamisiea et al. 2010). To allow the upper ocean to reach quasi-equilibrium (e.g., Capotondi et al. 2003), we spun up the model from rest with atmospheric forcing from 1979 repeatedly applied for 50 years, which provided the initial conditions for a control simulation of the 1979-2017 period. The atmospheric forcing is determined from two different methods using data from the JRA-55 product. Surface fluxes are either calculated based on atmospheric state variables and radiation using the aerodynamic bulk formula [i.e., similar to Luo et al. (2014)] or POP2 is forced directly by daily mean surface momentum fluxes, latent and sensible heat fluxes, solar and longwave radiation, and freshwater flux. By prescribing fluxes, we were able to isolate the relative roles of momentum and heat fluxes (freshwater flux was held constant) on forcing changes in Hawaii sea level, whereas, by calculating surface fluxes using the bulk formula method, which is similar to the procedure typically used in fully coupled models, we first quantified the sea level response to changes in the total surface forcing.

We conducted two pairs of experiments to quantify the Hawaii sea level effects of varying atmospheric conditions prior to or after the peak of the two strongest El Niño events. The first pair, which we call the El Niño termination experiments, involved either prescribing the atmosphere during 2016/17 (weak trade winds when the PMM was positive) to be like 1998/99 (strong trade winds, negative PMM), or vice versa. We did not alter 

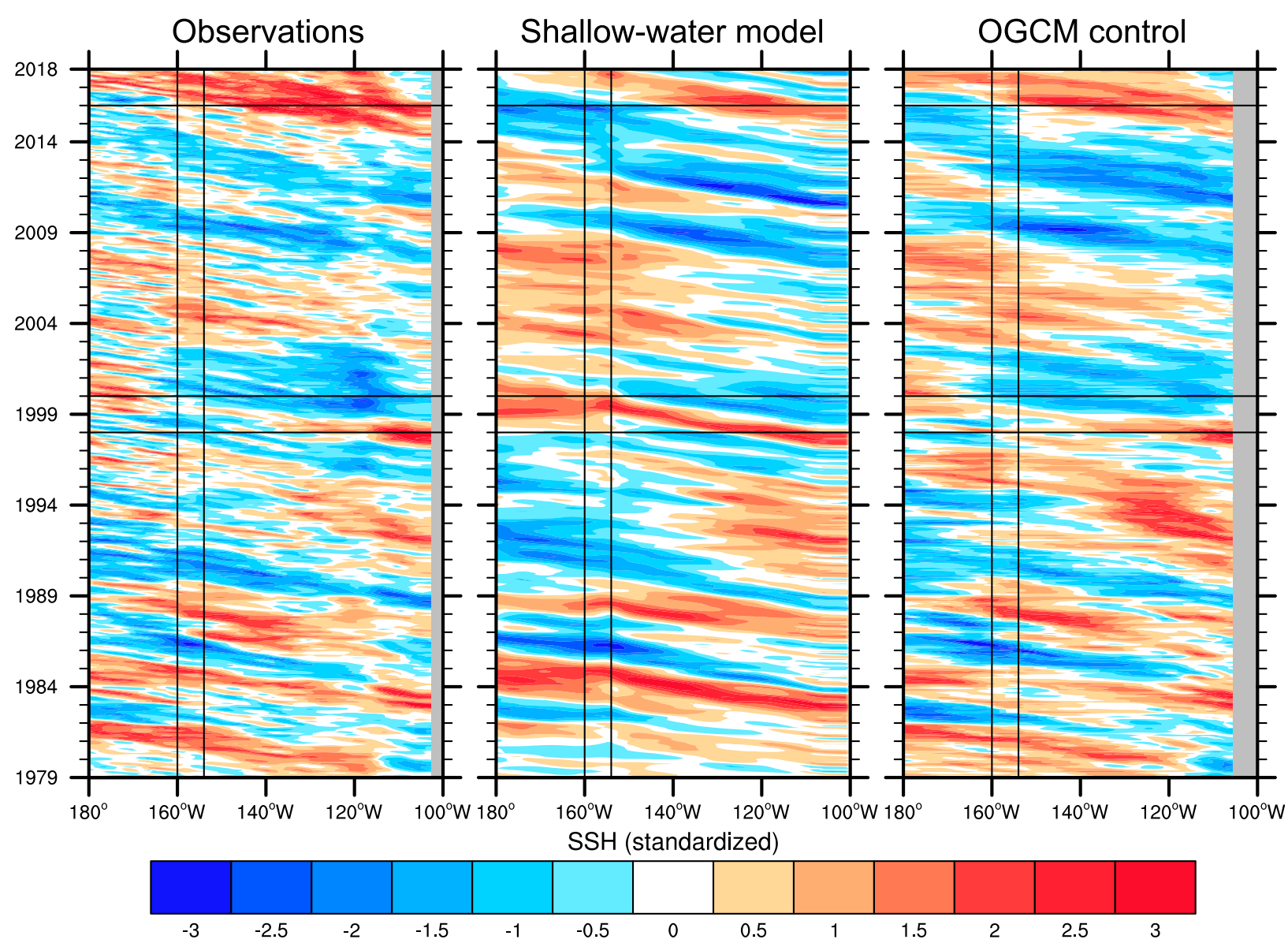

SSH (standardized)

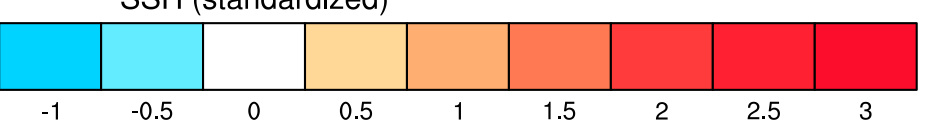

FIG. 11. Time vs longitude anomalies of observed and simulated SSH averaged between $18^{\circ}$ and $23^{\circ} \mathrm{N}$. Shown are SSH anomalies from the observations, inferred from the thermocline displacements in the shallow-water model, and the OGCM control simulation. Anomalies for each product have been standardized so that the temporal SD at each location is 1 . Standardized anomalies are with respect to the 1993-2017 monthly mean climatology and the linear trend (1979-2017) has been removed at each grid location. The longitude range of the main Hawaiian Islands $\left(160^{\circ}-154^{\circ} \mathrm{W}\right)$ is enclosed by the vertical lines. Horizontal lines enclose 1998/99 and 2016/17.

conditions around the peak of the El Niño events (1997 and 2015 were unchanged). The second pair, which we call the El Niño precursor experiments, involved either switching the 2013/14 conditions (developing weak El Niño) to be like 1995/96 (weak La Niña), or vice versa. Again, we did not change the atmospheric forcing around the peaks of the El Niño events; however, we matched the ocean initial conditions to what occurred in the control experiment at the time of the first altered atmospheric forcing (January 1995 or 2013) so that the ocean and atmosphere systems remained consistent. Together, the two pairs of experiments were used to simulate how the Hawaii sea level would have responded under four scenarios: 1) if the $2015 \mathrm{El}$ Niño was followed by strong trade winds as occurred after the 1997 El Niño, 2) if the 1997 El Niño was followed by weak trade winds as occurred after the $2015 \mathrm{El}$ Niño, 3) if the $2015 \mathrm{El}$ Niño was preceded by La Niña conditions as occurred prior to the $1997 \mathrm{El} \mathrm{Niño,} \mathrm{or} \mathrm{4)} \mathrm{if} \mathrm{the} 1997 \mathrm{El}$
Niño was preceded by weak El Niño conditions as occurred prior to the $2015 \mathrm{El}$ Niño. Finally, to isolate the thermodynamical and dynamical contributions to sea level variability, we reran the El Niño termination experiments with only atmospheric heat or momentum fluxes altered (i.e., by prescribing the respective fluxes rather than using the bulk formula to calculate them).

\section{2) INTERPRETATION}

It was only by using a state-of-the-art OGCM that we were able to successfully simulate the Hawaii sea level changes after the two strong El Niño events and achieve the highest explained variance on monthly $(58 \%)$ as well as interannual (69\%) time scales (Fig. 10). Both the 2017 extremely high sea level (+2 SD) and the near-normal sea level during 1999 are better simulated by the OGCM (Fig. 12) compared to the shallow-water model (Figs. 5c,d). The improvement of the OGCM over the linear regression model is more subtle, at least at annual time 


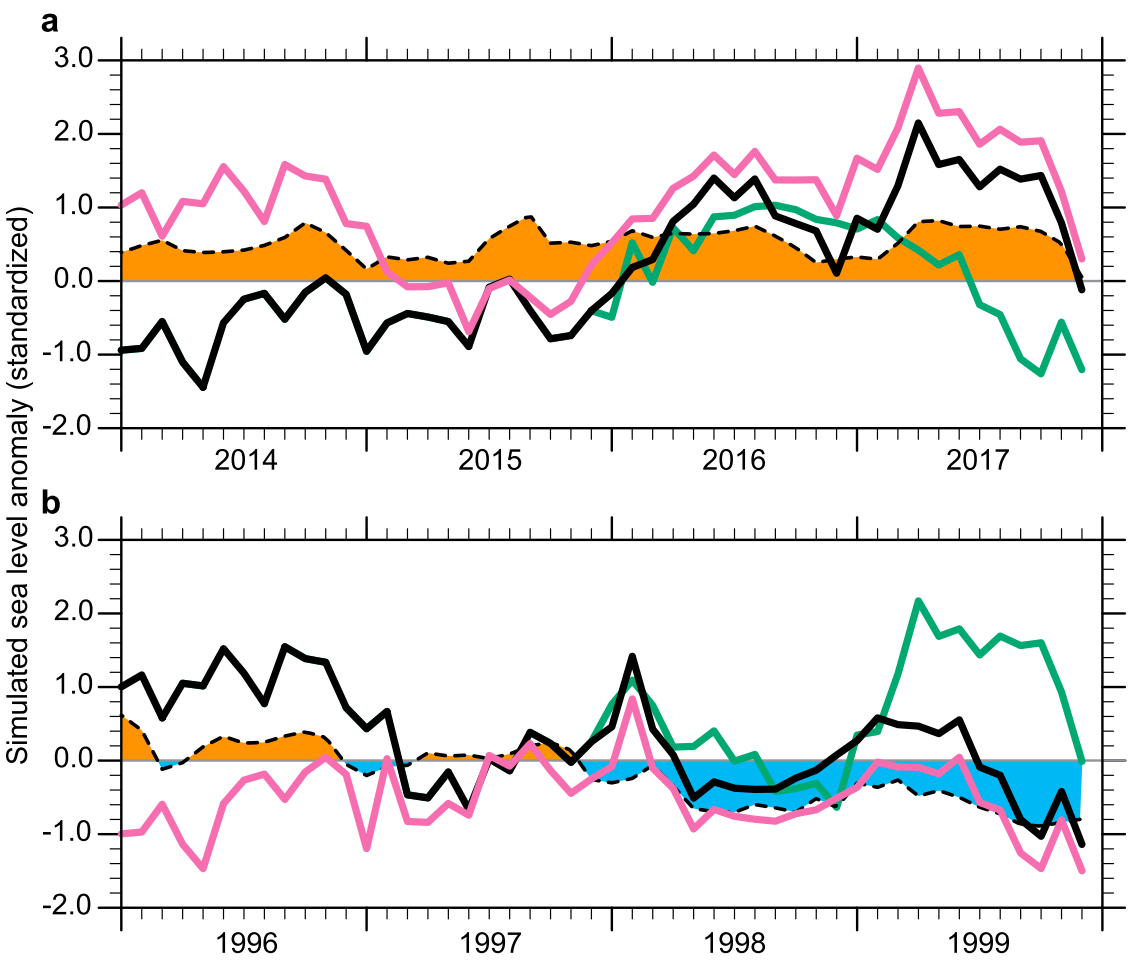

FIG. 12. Simulated sea level anomalies around Hawaii before, during, and after the two strong El Niño events using the OGCM with prescribed observed atmospheric forcing (black lines). (a) The sea level response to the $2015 \mathrm{El}$ Niño is modified from the control by replacing the atmospheric forcing so that either 2013/14 is similar to $1995 / 96$ (purple) or 2016/17 is similar to 1998/99 (green). (b) The sea level response to the $1997 \mathrm{El} \mathrm{Niño} \mathrm{is} \mathrm{modified} \mathrm{from} \mathrm{the} \mathrm{control}$ by replacing the atmospheric forcing so that either 1995/96 is similar to 2013/14 (purple) or $1998 / 99$ is similar to 2016/17 (green). Purple and green results are associated with the precursor and termination experiment pairs, respectively. Atmospheric conditions during the peak El Niño year (2015 or 1997) are unchanged in all experiments. The mixed layer buoyancy effect on sea level anomalies (thermosteric contribution from the upper $100 \mathrm{~m}$ of the control simulation) is indicated by the dashed lines and respective shading (orange: positive; blue: negative). Anomalies are with respect to the 1993-2017 monthly mean model climatology and standardized with respect to the control simulation (1979-2017) having a SD of 1.

scales (Fig. 10b). The control simulation captured the salient features of sea level variability observed around Hawaii (Fig. 10) and, in particular, the extremely high sea level during 2017 (>2 SD) and near-normal sea level during 1999 (Fig. 12). The westward propagation of high sea level anomalies was also more realistically simulated by the OGCM compared to using the shallow-water model (Fig. 11).

Considering that both the shallow-water model and OGCM are forced by similar wind stress, the more realistic OGCM simulation, which is also forced by heat fluxes, suggests that thermodynamic processes in the ocean influence the Hawaii sea level. To diagnose specifically the mixed layer buoyancy effect on Hawaii sea level anomalies following strong El Niño, we calculated the thermosteric contribution from the upper $100 \mathrm{~m}$ using the simulated ocean temperature profile. In fact, the contribution to sea level anomalies of upper-ocean density changes exceeded 0.5 SD during 2017 (Fig. 12a). Opposite density anomalies occurred during 1999 (Fig. 12b). Such density changes were associated with anomalous warming (2016/17; Fig. 7b) or cooling (1998/99; Fig. 7d) of the ocean mixed layer in much of the tropical North Pacific between Hawaii and Mexico during periods of either weak or strong trade winds, respectively (Figs. 7a,c).

To test the hypothesis that the atmospheric conditions after the peak of strong El Niño affect the Hawaii sea level simulated by the OGCM, we utilized the two socalled El Niño termination experiments with surface fluxes calculated using the bulk formula: 2016/17 conditions were replaced with 1998/99 and vice versa. As noted, a primary atmospheric difference between the two periods in the tropical northeastern Pacific was the 


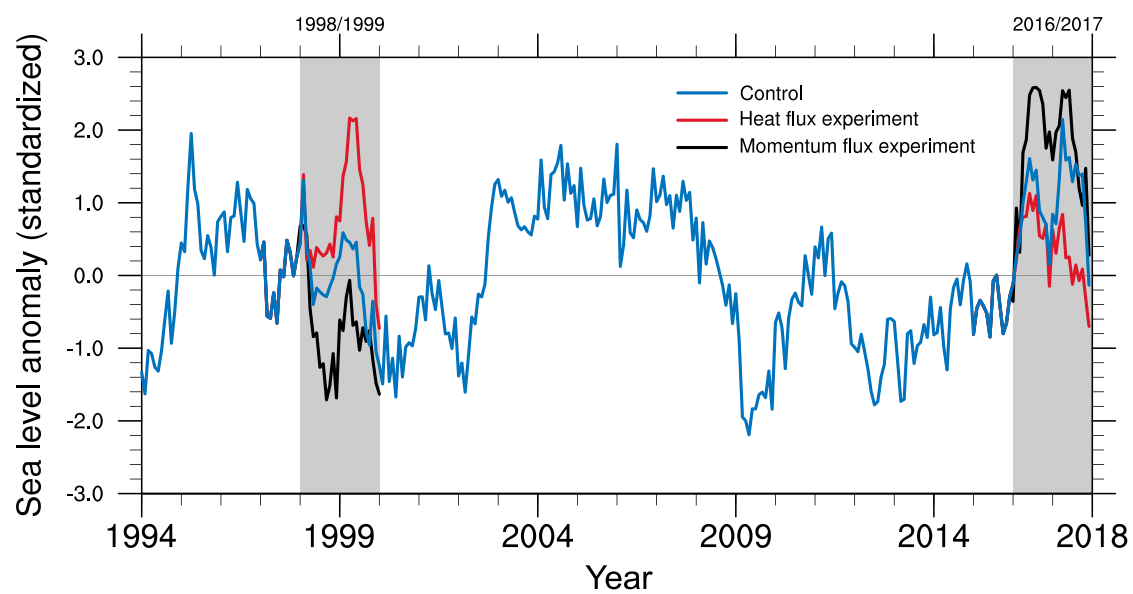

FIG. 13. Simulated sea level anomalies around Hawaii after the two strong El Niño events using the OGCM with prescribed atmospheric forcing so that either heat (red) or momentum (black) fluxes are modified from the control (blue). During the shaded years, either both latent and sensible heat or momentum surface fluxes are altered. The sea level response to the 2015 El Niño is modified from the control by replacing the atmospheric forcing so that 2016/17 is similar to 1998/99. The sea level response to the $1997 \mathrm{El} \mathrm{Niño} \mathrm{is} \mathrm{modified} \mathrm{from} \mathrm{the} \mathrm{control}$ by replacing the atmospheric forcing so that 1998/99 is similar to 2016/17. Anomalies are with respect to the 1993-2017 monthly mean model climatology and standardized with respect to the control simulation (1979-2017) having a SD of 1.

trade wind strength near and upstream of Hawaii (Fig. 4c). By prescribing stronger trade winds after the 2015 El Niño peaked, the 2017 extremely high sea levels ceased to occur (Fig. 12a). Instead, sea levels more than 1 SD below normal were simulated. On the other hand, by prescribing weaker trade winds after the 1997 El Niño, high sea levels were simulated during 1999 (Fig. 12b), which were of similar extreme magnitude to those observed in 2017 ( +2 SD).

Rerunning both termination experiments with only the heat flux altered (i.e., using the prescribed-flux method) produced similar results (red lines in Fig. 13), confirming that thermodynamical processes mostly determine the different Hawaii sea level responses after the two strong El Niño events. Switching only the surface heating conditions, so that $1998 / 99$ was like $2016 / 17$, caused the year of highest sea levels to also switch from 2017 to 1999. Likewise, replacing the 2016/17 heat flux with the enhanced surface cooling that occurred during the windier 1998/99 period caused a lowering of the simulated sea levels following the 2015 El Niño. Opposite changes occurred when only the momentum flux was altered (i.e., sea levels became higher during 2016/17 and lower during 1998/99; black lines in Fig. 13), which suggests that the wind stress curl after the $2015 \mathrm{El}$ Niño acted to diminish the recent high sea levels, compared to if the 1998/99 wind stress curl had occurred. Results of the prescribed momentum flux experiment are consistent with the observations that there was in fact more upwelling upstream of
Hawaii following the 2015 El Niño compared to after the 1997 event (Fig. 4c).

Alternatively to the demonstrated post-El Niño sensitivity of sea level to the heat and momentum fluxes associated with the trade winds, we hypothesized that the prolonged warm period during 2014/15 (McPhaden et al. 2015; Menkes et al. 2014) may have preconditioned the ocean for subsequent high sea levels at Hawaii; unlike after 1996/97, which began in La Niña conditions (Fig. 1b). Whereas there are pronounced differences in the winds and sea levels during these periods (i.e., Fig. 3), the precursor experiments show that altering the ocean and atmosphere before the peak of El Niño in 2015 , so that $2013 / 14$ was like $1995 / 96$ (i.e., shortening the recent El Niño), actually caused the simulated Hawaii sea level to be higher than the control (Fig. 12a). Conversely, prolonging the previous strong El Niño, by prescribing $1995 / 96$ to be like $2013 / 14$, resulted in somewhat lower sea levels during 1999 compared to the control (Fig. 12b). Neither of these so-called El Niño precursor experiments suggests that the recent prolonged warm event, and associated 2013/14 oceanatmosphere conditions, substantially contributed to the record-high sea levels at Hawaii during 2017. From the El Niño termination and precursor experiments come two particularly salient results toward explaining the Hawaii sea level response to strong El Niño. First, the wind pattern after the demise of El Niño determines the potential for extremely high sea levels at Hawaii. Second, longer-duration El Niño events do not cause 
higher sea levels at Hawaii. The second result disproves our alternative hypothesis that the 2017 high sea levels were somehow associated with the prolonged El Niño conditions that began in 2014. In fact, by making 2013/14 to be more La Niña-like, by prescribing 1995/96 oceanatmosphere conditions, the simulated Hawaii sea level anomaly was nearly $1 \mathrm{SD}$ higher than the control (Fig. 12a). Furthermore, by replacing the momentum flux during 2016/17 with 1998/99 conditions so that more downwelling occurred after the 2015 El Niño, while keeping the heat flux as observed, the simulated high sea levels increased during both 2016 and 2017 (Fig. 13). Therefore, the observed 2017 anomalies should not be considered an upper bound on the possible amplitude or occurrence of future high sea levels.

As is clear from the OGCM experiments, the trade wind strength provides an important control primarily through surface heat flux changes for whether, or not, high sea levels will occur at Hawaii after strong El Niño. Observations of the sea level-trade wind-ENSO relationship (Fig. 14a), while limited by record length, support such a mechanism of sea level control. Since 1979, the majority of months that sea levels were extremely high at Hawaii ( $>1$ SD; shaded orange in Fig. 14a) occurred when trade winds tended to be weak (34 out of 61 months), as inferred from positive PMM ( $>0.5$ SD; lead 8 months). The Hawaii sea level relationship after strong El Niño is comparatively weaker (18 out of 61 months were extremely high 19 months after Niño-3 peaked above $1 \mathrm{SD}$ ), although almost all low sea level events ( $<-1$ SD; shaded blue in Fig. 14a) follow the cool phase of ENSO (i.e., La Niña; Niño-3 $<-0.5$ SD). In combining these two relationships, our multiple linear regression model of the sea level response to ENSO and trade wind strength, as well as Ekman dynamics (Fig. 9c), predicts that the highest sea levels at Hawaii will occur when both the lagged-Niño-3 and PMM indices are positive (i.e., weak trade winds following strong El Niño). The only observation of such conditions is the 2017 high sea level event, which appears alone in the upper-right quadrant of Fig. 14a.

\section{Future change}

Coupled ocean-atmosphere climate models such as CMIP5 (Taylor et al. 2012), which simulate well the observed sea level interannual variability in the tropical Pacific (e.g., Yin et al. 2010), provide an opportunity to assess the likelihood of conditions associated with the 2017 high sea levels occurring in the past or future. Following a recent study that found an increase of the future interannual sea level variability in most of the tropical Pacific (Widlansky et al. 2015), including an unexplained $10 \%$ increase around Hawaii, we assessed the greenhouse warming projections in CMIP5 models (Tables 2 and 3). We specifically quantified the Hawaii SSH variability related to changes in the future occurrence of positive PMM conditions after strong El Niño events. Increasing joint occurrence of such is consistent with more frequent high sea level events at Hawaii and, hence, also the increasing regional sea level variability identified in CMIP5 projections.

The methods of assessing CMIP5 are similar to those employed in Widlansky et al. (2015), and this paragraph is derived from there with minor modifications. Here, though, we specifically consider the SSH and SST (used to describe the PMM and El Niño indices) variability around Hawaii. We assessed one experiment from each model, covering the period 1911-2100 using historical anthropogenic and natural forcings to 2005 and then the future emission scenario (RCP8.5), which ignores volcanic and other natural aerosols, for the later 95 years. For each model, we first interpolate the dynamic SSH and SST to a uniform $1^{\circ}$ latitude $\times 1^{\circ}$ longitude grid using bilinear interpolation. We calculated the monthly anomalies of both variables with respect to the last 30 years of the historical period (1976-2005). We derived changes in the frequency of positive PMM after El Niño events (Fig. 14b) by comparing the first 95 years (historical period) to the later 95 years (future period); thus, there was a large ratio between the climate change signal and any higherfrequency variability internal to the models. In assessing the future occurrence of Hawaii sea level anomalies (Fig. 14c), we removed each model's global average SSH anomaly at each month but retained the spatial patterns of any long-term sea level trends inherent to the model.

We examined the joint occurrence of positive PMMlike events $(>0.5 \mathrm{SD})$ following strong El Niño-like events (Niño-3 $>1$ SD) in the CMIP5 historical period by projecting simulated monthly SST anomalies from each model onto the observed SST patterns associated with the respective indices (Figs. 6c,d). The number of months for PMM lagging Niño-3 was determined for each model based on the CMIP5 correlations of the indices and the oceanic conditions around Hawaii (inferred from SST and sea level, respectively; Table 2). This exercise produces a multimodel average count of 59 joint occurrences during 1911-2005. (Table 3 shows the historical and future occurrences for each model.) With unabated greenhouse warming (i.e., the RCP8.5 future emissions experiment, 2006-2100), we found that the occurrence of strong El Niño followed by positive PMM conditions is likely to increase during the twentyfirst century (72 months on average; see also Fig. 14b). 
a

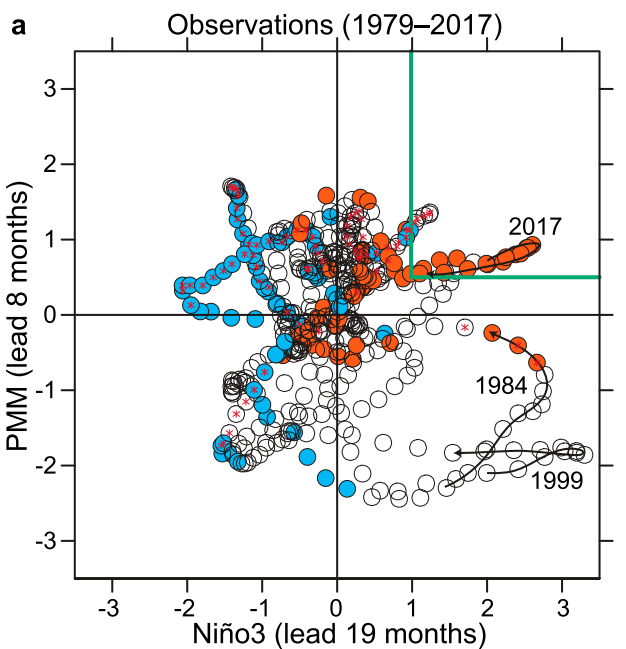

c Hawaii $\left(18^{\circ}-23^{\circ} \mathrm{N}, 160^{\circ} \mathrm{W}-154^{\circ} \mathrm{W}\right)$

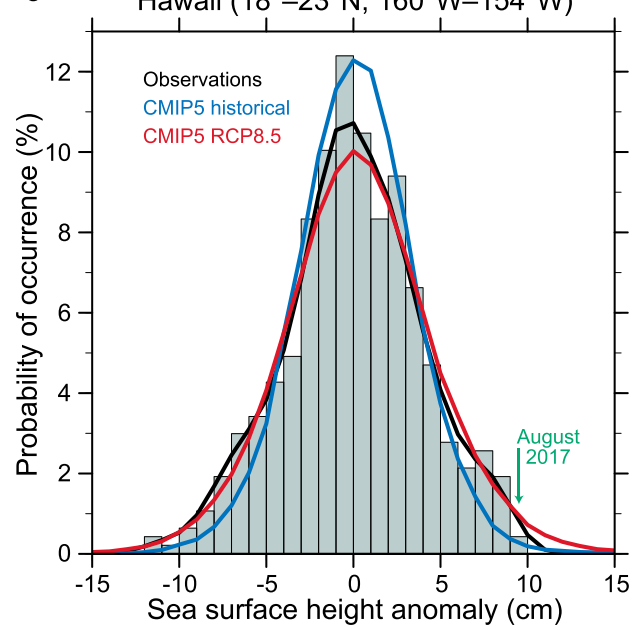

b Future change (RCP8.5 minus historical)

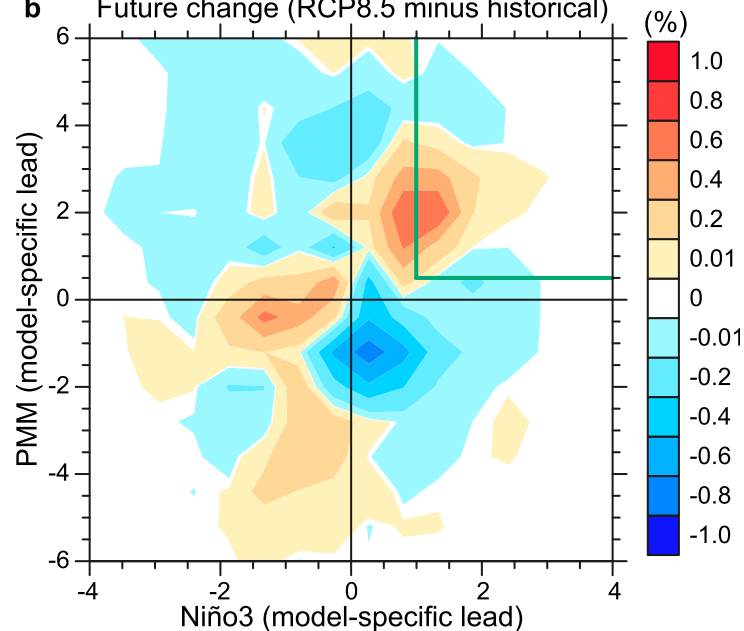

d

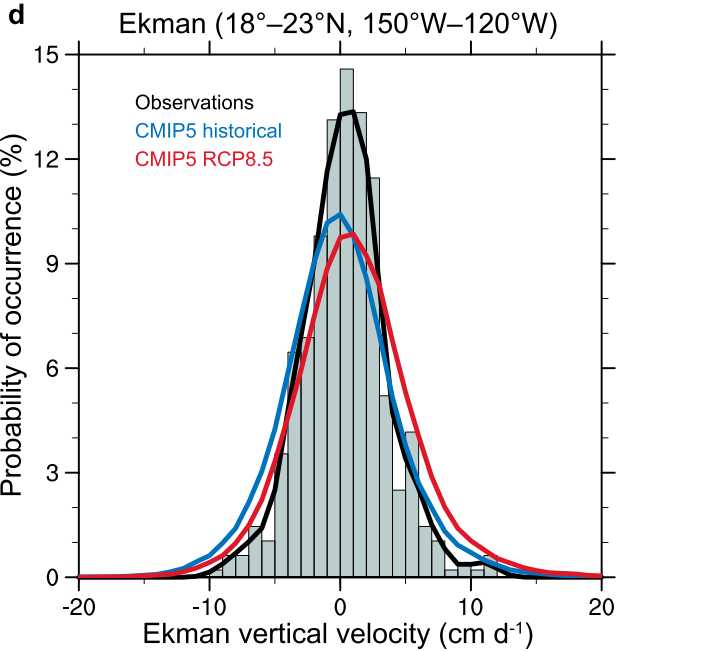

FIG. 14. Observed relationship between ENSO and the PMM, its future change under greenhouse warming, and the changing probability distributions of SSH and Ekman vertical velocity anomalies. (a) Lagged relationship between the Niño-3 (19 month) and PMM (8 month) standardized indices. Circles are colored by the monthly sea level anomaly at Hawaii (orange: $>1$ SD; blue: $<-1$ SD). Months during years following the strongest El Niño events are indicated by the curved arrows (1984, 1999, and 2017). The green box (Niño-3 > 1 SD and PMM > 0.5 SD) encloses the 2017 high sea level event. Red asterisks indicate when upwelling was strong ( $>1$ SD; Fig. 1b) and the PMM index was not used in the regression model. (b) Projected increase in positive PMM events (weak trade winds) following strong El Niño events from the historical to future period (1774 vs 2163 simulated months in the green box when Niño-3 $>1$ SD and PMM $>0.5$ SD). (c),(d) Distribution of observed (gray bars; 1979-2017) and simulated (CMIP5; 1911-2005 and 2006-2100) SSH and Ekman vertical velocity monthly anomalies around and upstream of Hawaii, respectively. A kernel smoothing function (normal distribution; bin width of $1 \mathrm{~cm}$ ) is applied to each distribution of SSH: black (observations), blue (historical), and red (RCP8.5) lines. The observed August 2017 sea level anomaly is indicated by an arrow (satellite altimetry with respect to the 1993-2017 climatology; linear trend removed). (d) For Ekman monthly anomalies (positive: upwelling; negative: downwelling), a kernel smoothing function (normal distribution; bin width of $1 \mathrm{~cm} \mathrm{day}^{-1}$ ) is similarly applied to each distribution. The mean of RCP8.5 is $1.1 \mathrm{~cm} \mathrm{day}^{-1}$ more than that of the historical, which suggests a higher probability of upwelling for the twenty-first century. The Ekman averaging region $\left(18^{\circ}-23^{\circ} \mathrm{N}\right.$, $150^{\circ}-120^{\circ} \mathrm{W}$ ) is shown in Figs. 3 and 4.

The future increase is robust across CMIP5 (21 out of 30 models; 57 vs 81 months on average among the increasing subset). Less likely to occur in the future projection are conditions like 1999 when the PMM was negative after a strong El Niño (i.e., lower-right quadrants of Figs. 14a,b) and the Hawaii sea level was near normal. These results are consistent with modeling evidence that the PMM is likely to become more energetic this century as the ocean-atmosphere coupling strengthens in the tropical North Pacific (Liguori and Di Lorenzo 2018). 
TABLE 2. Historical statistics of CMIP5 models. The correlations and month of maximum lead between the Niño-3-like and PMM-like indices with Hawaii sea level and ocean temperature, respectively, are listed for available models (long dashes indicates missing data). Temperature data are from the uppermost ocean level for each model. Italic numbers are not significant above the $95 \%$ confidence level (testing method is as discussed in section 3a). (Expansions of acronyms are available online at http://www.ametsoc.org/ PubsAcronymList.)

\begin{tabular}{|c|c|c|c|c|}
\hline \multirow[b]{2}{*}{ Model } & \multicolumn{2}{|c|}{ Niño-3-like and sea level } & \multicolumn{2}{|c|}{ PMM-like and ocean temperature } \\
\hline & Correlation & Lead (months) & Correlation & Lead (months) \\
\hline ACCESS1.0 & 0.27 & 9 & 0.61 & 2 \\
\hline ACCESS1.3 & 0.37 & 9 & 0.32 & 2 \\
\hline BCC-CSM1.1 & 0.13 & 16 & 0.46 & 0 \\
\hline BCC-CSM1.1-m & 0.17 & 17 & 0.41 & 0 \\
\hline CanESM2 & 0.27 & 13 & 0.61 & 3 \\
\hline CCSM4 & 0.53 & 10 & 0.62 & 0 \\
\hline CESM1-BGC & 0.26 & 9 & 0.50 & 1 \\
\hline CMCC-CESM & 0.57 & 18 & 0.71 & 3 \\
\hline CMCC-CM & 0.29 & 9 & 0.54 & 0 \\
\hline CMCC-CMS & 0.52 & 19 & 0.63 & 2 \\
\hline CNRM-CM5 & - & - & - & - \\
\hline CSIRO-Mk3.6.0 & 0.23 & 9 & 0.79 & 5 \\
\hline EC-EARTH & 0.24 & 14 & 0.57 & 0 \\
\hline FGOALS-g2 & 0.10 & 15 & 0.45 & 0 \\
\hline FIO-ESM & 0.76 & 11 & 0.43 & 0 \\
\hline GFDL CM3 & 0.27 & 16 & 0.49 & 0 \\
\hline GFDL-ESM2G & 0.55 & 18 & 0.77 & 2 \\
\hline GFDL-ESM2M & 0.58 & 13 & 0.66 & 1 \\
\hline GISS-E2-R & 0.10 & 10 & 0.53 & 1 \\
\hline GISS-E2-R-CC & 0.10 & 12 & 0.48 & 1 \\
\hline HadGEM2-CC & 0.03 & 36 & 0.59 & 4 \\
\hline HadGEM2-ES & 0.27 & 18 & 0.70 & 1 \\
\hline INM-CM4 & 0.28 & 36 & 0.62 & 2 \\
\hline IPSL-CM5A-LR & 0.40 & 8 & 0.66 & 2 \\
\hline IPSL-CM5A-MR & 0.32 & 18 & 0.71 & 1 \\
\hline IPSL-CM5B-LR & 0.10 & 11 & 0.08 & 27 \\
\hline MIROC5 & 0.75 & 9 & 0.65 & 0 \\
\hline MIROC-ESM & - & - & - & - \\
\hline MIROC-ESM-CHEM & 0.65 & 10 & 0.80 & 2 \\
\hline MPI-ESM-LR & 0.36 & 14 & 0.75 & 3 \\
\hline MPI-ESM-MR & 0.62 & 12 & 0.75 & 1 \\
\hline MRI-CGCM3 & 0.12 & 19 & 0.19 & 0 \\
\hline MRI-ESM1 & 0.04 & 19 & 0.10 & 0 \\
\hline NorESM1-M & 0.41 & 11 & 0.70 & 3 \\
\hline NorESM1-ME & 0.55 & 11 & 0.66 & 3 \\
\hline
\end{tabular}

As in Widlansky et al. (2015), we used a bootstrap resampling method of the CMIP5 ensemble to examine whether the change in frequency of positive PMM occurrence after strong El Niño events is statistically significant. The counts of joint occurrence from the 30 models in the historical and future 95-yr periods (Table 3) were randomly resampled with replacement to construct 10000 realizations. The SD of the future minus historical differences of extreme months in the intermodel realization is 183 months, which is more than 2 times smaller than the total difference between the historical and the future periods at 389 months, indicating statistical significance of the multimodel difference above the $95 \%$ confidence level. A twosided $t$ test of the difference of means between the historical and future periods was similarly positive for significance at that level.

Previous studies have shown that climate model projections mostly agree that the atmospheric and sea level effects associated with strong El Niño are likely to become more frequent with greenhouse warming (Cai et al. 2015, 2018; Widlansky et al. 2015). For Hawaii specifically, the probability of monthly high sea level anomalies with similar magnitude to the 2017 event ( $>10 \mathrm{~cm}$ above normal; Fig. 14c) increases in CMIP5 this century. More generally, the SD of Hawaii sea level increases from $3.2 \mathrm{~cm}$ during the historical simulation to $3.7 \mathrm{~cm}$ during the twenty-first century (the change of multimodel mean variability is significant above the $95 \%$ confidence level using both the $t$ test and bootstrap 
TABLE 3. Future change statistics of CMIP5 models. The projected Hawaii sea level variability (SD of regional SSH; black box in Fig. 2), occurrence of weak trade winds after strong El Niño, and Ekman variability upstream of Hawaii (SD; gray boxes in Figs. 3 and 4 ) are listed for available models. The numbers of months are calculated based on projections of Niño-3 $>1$ SD and PMM $>0.5$ SD at modelspecific leads (see Table 2). Boldface numbers indicate an increase from the historical (1911-2005) to the future (2006-2100, RCP8.5 scenario) periods; italics indicate a decrease. Three models were excluded from the lagged-Niño-3 and PMM calculations, as well as for Ekman variability (different models) due to missing data (long dashes). For comparison, the observed SD of Hawaii sea level was $3.9 \mathrm{~cm}$, the occurrence of lagged-Niño-3 > 1 SD and PMM indices > 0.5 SD was 25 months during 1979-2017, and the SD of Ekman vertical velocity was $3.2 \mathrm{~cm}$ day $^{-1}$.

\begin{tabular}{|c|c|c|c|}
\hline Model & Hawaii sea level variability $(\mathrm{cm})$ & Weak trade winds after El Niño (months) & Ekman variability $\left(\mathrm{cm} \mathrm{day}^{-1}\right)$ \\
\hline ACCESS1.0 & 2.6/3.5 & $135 / 172$ & $4.3 / 4.1$ \\
\hline ACCESS1.3 & $2.6 / 4.3$ & $162 / 193$ & $3.8 / 4.7$ \\
\hline BCC-CSM1.1 & 3.4/3.6 & 115/117 & 4.5/7.1 \\
\hline BCC-CSM1.1-m & $2.5 / 2.9$ & $136 / 135$ & $4.5 / 4.7$ \\
\hline CanESM2 & $2.2 / 2.8$ & $146 / 169$ & $3.9 / 4.0$ \\
\hline CCSM4 & $3.3 / 3.0$ & $150 / 145$ & $4.7 / 4.0$ \\
\hline CESM1-BGC & $3.5 / 3.0$ & $142 / 153$ & $4.7 / 4.3$ \\
\hline CMCC-CESM & $4.3 / 6.0$ & $151 / 160$ & $6.3 / 5.9$ \\
\hline CMCC-CM & 2.2/3.1 & $120 / 140$ & $5.6 / 6.1$ \\
\hline CMCC-CMS & $3.0 / 4.0$ & $142 / 201$ & $5.6 / 6.1$ \\
\hline CNRM-CM5 & $2.9 / 2.8$ & - & $5.1 / 4.9$ \\
\hline CSIRO-Mk3.6.0 & $3.9 / 4.2$ & $105 / 149$ & $3.6 / 3.8$ \\
\hline EC-EARTH & $3.7 / 4.3$ & 97/135 & - \\
\hline FGOALS-g2 & $2.5 / 3.4$ & $146 /-$ & $4.0 / 4.3$ \\
\hline FIO-ESM & $4.1 / 3.7$ & $247 / 220$ & $5.4 / 4.5$ \\
\hline GFDL CM3 & 2.9/3.2 & $125 / 156$ & $5.6 / 6.6$ \\
\hline GFDL-ESM2G & $4.7 / 5.0$ & $105 / 111$ & $6.3 / 6.6$ \\
\hline GFDL-ESM2M & $4.5 / 4.0$ & $\mathbf{8 0 / 1 1 0}$ & $6.7 / 6.5$ \\
\hline GISS-E2-R & $2.5 / 2.9$ & $139 / 124$ & $4.8 / 4.5$ \\
\hline GISS-E2-R-CC & $2.7 / 2.9$ & $142 / 160$ & - \\
\hline HadGEM2-CC & 3.3/3.6 & $143 / 151$ & $4.6 / 5.1$ \\
\hline HadGEM2-ES & 3.3/3.4 & $120 / 168$ & $4.7 / 5.3$ \\
\hline INM-CM4 & $3.2 / 3.0$ & $147 / 133$ & $5.2 / 4.8$ \\
\hline IPSL-CM5A-LR & $3.7 / 3.4$ & $140 / 125$ & $4.9 / 4.7$ \\
\hline IPSL-CM5A-MR & $3.5 / 3.7$ & $121 / 124$ & $4.6 / 5.1$ \\
\hline IPSL-CM5B-LR & $3.1 / 3.3$ & $137 / 163$ & $5.3 / 5.2$ \\
\hline MIROC5 & $4.7 / 5.5$ & $82 / 91$ & $5.5 / 6.2$ \\
\hline MIROC-ESM & 2.9/4.1 & - & $5.0 / 4.7$ \\
\hline MIROC-ESM-CHEM & 2.8/3.7 & $121 / 91$ & $4.8 / 4.6$ \\
\hline MPI-ESM-LR & $3.7 / 4.4$ & $167 / 165$ & $5.5 / 5.9$ \\
\hline MPI-ESM-MR & $3.6 / 4.7$ & $157 / 140$ & $5.4 / 5.7$ \\
\hline MRI-CGCM3 & 2.7/3.0 & $101 / 142$ & $4.9 / 4.9$ \\
\hline MRI-ESM1 & $2.3 / 2.7$ & $99 / 159$ & - \\
\hline NorESM1-M & 3.1/3.3 & $163 / 161$ & $4.7 / 3.9$ \\
\hline NorESM1-ME & $3.2 / 3.8$ & $209 / 172$ & $4.9 / 4.1$ \\
\hline
\end{tabular}

methods) and 28 out of 35 models agree on the increase (3.1 vs $3.8 \mathrm{~cm}$ among the subset; Table 3 ). The increasing sea level variability at Hawaii is not explained by projected changes in Ekman pumping (Table 3 and Fig. 14 d), which become only $2 \%$ more variable with greenhouse warming compared to a $13 \%-16 \%$ increase for sea level (the range being related to whether the SDs of the historical and future periods are rounded to the nearest millimeter prior to, or after, taking the respective multimodel averages). Unlike the statistically robust projection of increasing Hawaii sea level variability, the Ekman pumping future variability change is not significantly different from the intermodel characteristics during the historical period and, furthermore, only half of the models agree on any increase.

\section{Discussion}

Should trade winds near Hawaii weaken with greenhouse warming (i.e., a trend toward more positive PMM conditions), which would decrease the surface cooling of the ocean mixed layer and thus increase its buoyancy (Thompson and Ladd 2004), it would be reasonable to expect more frequent high sea levels following future strong El Niño events. Such a change, with oceanic anomalies becoming more likely to propagate westward 
across the tropical North Pacific, rather than to remain near the coast, may determine potentially far-reaching climate implications (Jacobs et al. 1994). Considering that oceanic anomalies take 5-10 years to traverse the subtropical and midlatitude Pacific, it will require several more years to know whether or not the positive PMM following the 2015 El Niño contributed to larger decadal perturbations compared to the negative PMM after the 1997 El Niño.

In addition to affecting the large-scale sea level pattern, the trade winds could also force sea level variability around Hawaii via local processes, in particular through the wind stress curl generated by interaction with island topography (Fig. 4, insets). Understanding the impact of such localized mechanisms and potential differences after the two strong El Niño events requires further study. Addressing such issues will require OGCM experiments with much higher spatial resolution than we utilized, in addition to requiring surface forcing products that resolve well the complex winds around the Hawaiian Islands. Determining such localized oceanic responses to trade wind variability may likewise have large-scale climate implications, especially in the northwestern Pacific, which is strongly affected by the wind wake to the lee of Hawaii (Xie et al. 2001).

Increasing occurrence of interannual high sea levels around Hawaii will accelerate the regional risks posed by remotely-generated surface waves (Cheriton et al. 2016) or storm surges during hurricanes (Widlansky et al. 2019), which will be exacerbated by long-term sea level rise (Sweet et al. 2017). More frequent high sea levels like during 2017 will also increase the probability of exceeding local thresholds for causing nuisance-level flooding around times of high tides (Sweet et al. 2014), which will likely become more detrimental with increasing occurrence (Thompson et al. 2019). Forecasting sea level fluctuations (Widlansky et al. 2017), if skillful predictions are achievable at sufficient lead times, may help alert stakeholders in Hawaii and elsewhere that experiences interannual variability to prepare assets along vulnerable coasts (Anderson et al. 2018) for when future high sea level events occur.

Acknowledgments. We acknowledge the World Climate Research Programme's Working Group on Coupled Modelling, which is responsible for CMIP, and we thank the climate modeling groups for producing and making available their model output. This work was supported by NOAA Grant NA17OAR4310110. The authors thank three anonymous reviewers for constructive feedback that lead to improvements of the study.

\section{REFERENCES}

Alexander, M. A., H. Seo, S. P. Xie, and J. D. Scott, 2012: ENSO's impact on the gap wind regions of the eastern tropical Pacific Ocean. J. Climate, 25, 3549-3565, https://doi.org/10.1175/ JCLI-D-11-00320.1.

Anderson, T. R., C. H. Fletcher, M. M. Barbee, B. M. Romine, S. Lemmo, and J. M. S. Delevaux, 2018: Modeling multiple sea level rise stresses reveals up to twice the land at risk compared to strictly passive flooding methods. Sci. Rep., 8, 14484, https:// doi.org/10.1038/s41598-018-32658-x.

Balmaseda, M. A., K. Mogensen, and A. T. Weaver, 2013: Evaluation of the ECMWF Ocean Reanalysis System ORAS4. Quart. J. Roy. Meteor. Soc., 139, 1132-1161, https://doi.org/10.1002/qj.2063.

Cai, W., and Coauthors, 2015: ENSO and greenhouse warming. Nat. Climate Change, 5, 849-859, https://doi.org/10.1038/nclimate2743. , and Coauthors, 2018: Increased variability of eastern Pacific El Niño under greenhouse warming. Nature, 564, 201-206, https://doi.org/10.1038/s41586-018-0776-9.

Caldwell, P. C., M. A. Merrifield, and P. R. Thompson, 2015: Sea level measured by tide gauges from global oceans-the Joint Archive for Sea Level holdings (NCEI Accession 0019568), version 5.5. NOAA/National Centers for Environmental Information, accessed 15 December 2018, https://doi.org/ 10.7289/V5V40S7W

Capotondi, A., M. A. Alexander, and C. Deser, 2003: Why are there Rossby wave maxima in the Pacific at $10^{\circ} \mathrm{S}$ and $13^{\circ} \mathrm{N}$ ? J. Phys. Oceanogr., 33, 1549-1563, https://doi.org/10.1175/2407.1.

Chang, C.-H., and Coauthors, 2012: East Pacific Ocean eddies and their relationship to subseasonal variability in Central American wind jets. J. Geophys. Res., 117, C10001, https:// doi.org/10.1029/2011JC007315.

Chelton, D. B., and R. E. Davis, 1982: Monthly mean sea-level variability along the west coast of North America. J. Phys. Oceanogr., 12, 757-784, https://doi.org/10.1175/1520-0485(1982) 012<0757:MMSLVA>2.0.CO;2.

_ , and M. G. Schlax, 1996: Global observations of oceanic Rossby waves. Science, 272, 234-238, https://doi.org/10.1126/ science.272.5259.234.

Chen, X., X. Zhang, J. A. Church, C. S. Watson, M. A. King, D. Monselesan, B. Legresy, and C. Harig, 2017: The increasing rate of global mean sea-level rise during 1993-2014. Nat. Climate Change, 7, 492-495, https://doi.org/10.1038/ nclimate 3325.

Cheriton, O. M., C. D. Storlazzi, and K. J. Rosenberger, 2016: Observations of wave transformation over a fringing coral reef and the importance of low-frequency waves and offshore water levels to runup, overwash, and coastal flooding. J. Geophys. Res. Oceans, 121, 3121-3140, https://doi.org/ 10.1002/2015JC011231.

Chiang, J. C., and D. J. Vimont, 2004: Analogous Pacific and Atlantic meridional modes of tropical atmosphere-ocean variability. J. Climate, 17, 4143-4158, https://doi.org/10.1175/ JCLI4953.1.

Dee, D. P., and Coauthors, 2011: The ERA-Interim reanalysis: Configuration and performance of the data assimilation system. Quart. J. Roy. Meteor. Soc., 137, 553-597, https://doi.org/ doi:10.1002/qj.828.

Delcroix, T., 1998: Observed surface oceanic and atmospheric variability in the tropical Pacific at seasonal and ENSO timescales: A tentative overview. J. Geophys. Res., 103, 18 611-18 633, https://doi.org/10.1029/98JC00814. 
Fasullo, J. T., and P. R. Gent, 2017: On the relationship between regional ocean heat content and sea surface height. J. Climate, 30, 9195-9211, https://doi.org/10.1175/JCLI-D-16-0920.1.

Fiedler, P. C., 2010: Comparison of objective descriptions of the thermocline. Limnol. Oceanogr. Methods, 8, 313-325, https:// doi.org/10.4319/lom.2010.8.313.

Firing, Y. L., and M. A. Merrifield, 2004: Extreme sea level events at Hawaii: Influence of mesoscale eddies. Geophys. Res. Lett., 31, L24306, https://doi.org/10.1029/2004GL021539.

,,- T. A. Schroeder, and B. Qiu, 2004: Interdecadal sea level fluctuations at Hawaii. J. Phys. Oceanogr., 34, 2514-2524, https://doi.org/10.1175/JPO2636.1.

Fu, L.-L., and B. Qiu, 2002: Low-frequency variability of the North Pacific Ocean: The roles of boundary- and wind-driven baroclinic Rossby waves. J. Geophys. Res., 107, 3220, https:// doi.org/10.1029/2001JC001131.

Huang, B., and Coauthors, 2017: Extended Reconstructed Sea Surface Temperature version 5 (ERSSTv5): Upgrades, validations, and intercomparisons. J. Climate, 30, 8179-8205, https://doi.org/10.1175/JCLI-D-16-0836.1.

Hughes, C. W., I. Fukumori, S. M. Griffies, J. M. Huthnance, S. Minobe, P. Spence, K. R. Thompson, A. Wise, 2019: Sea level and the role of coastal trapped waves in mediating the influence of the open ocean on the coast. Surv. Geophys., 40, 1467-1492, https://doi.org/10.1007/S10712-019-09535-X.

Jacobs, G. A., H. E. Hurlburt, J. C. Kindle, E. J. Metzger, J. L. Mitchell, W. J. Teague, and A. J. Wallcraft, 1994: Decadescale trans-Pacific propagation and warming effects of an El Niño anomaly. Nature, 370, 360-363, https://doi.org/10.1038/ $370360 \mathrm{a} 0$.

Johnson, M. A., and J. J. O'Brien, 1990: The role of coastal Kelvin waves on the northeast Pacific Ocean. J. Mar. Syst., 1, 29-38, https://doi.org/10.1016/0924-7963(90)90085-O.

Kobayashi, S., and Coauthors, 2015: The JRA-55 reanalysis: General specifications and basic characteristics. J. Meteor. Soc. Japan, 93, 5-48, https://doi.org/10.2151/jmsj.2015-001.

L'Heureux, M. L., and Coauthors, 2017: Observing and predicting the 2015/16 El Niño. Bull. Amer. Meteor. Soc., 98, 1363-1382, https://doi.org/10.1175/BAMS-D-16-0009.1.

Liguori, G., and E. Di Lorenzo, 2018: Meridional modes and increasing Pacific decadal variability under anthropogenic forcing. Geophys. Res. Lett., 45, 983-991, https://doi.org/ 10.1002/2017GL076548.

Lin, J.-L., W. Han, and X. Lin, 2008: Observational analysis of the wind-evaporation-SST feedback over the tropical Pacific Ocean. Atmos. Sci. Lett., 9, 231-236, https://doi.org/ 10.1002/asl.195

Luo, Y., J. Lu, and W. Liu, 2014: Understanding the El Niñolike oceanic response in the tropical Pacific to global warming. Climate Dyn., 45, 1945-1964, https://doi.org/ 10.1007/S00382-014-2448-2.

McGregor, S., N. J. Holbrook, and S. B. Power, 2007: Interdecadal sea surface temperature variability in the equatorial Pacific Ocean. Part I: The role of off-equatorial wind stresses and oceanic Rossby waves. J. Climate, 20, 2643-2658, https:// doi.org/10.1175/JCLI4145.1.

, A. Timmermann, N. Schneider, M. F. Stuecker, and M. H. England, 2012: The effect of the South Pacific convergence zone on the termination of El Niño events and the meridional asymmetry of ENSO. J. Climate, 25, 5566-5586, https:// doi.org/10.1175/JCLI-D-11-00332.1.

McPhaden, M. J., and S. P. Hayes, 1991: On the variability of winds, sea surface temperature, and surface layer heat content in the western equatorial Pacific. J. Geophys. Res., 96, 3331-3342, https://doi.org/10.1029/90JC01726.

_ A. Timmermann, M. J. Widlansky, M. A. Balmaseda, and T. N. Stockdale, 2015: The curious case of the El Niño that never happened: A perspective from 40 years of progress in climate research and forecasting. Bull. Amer. Meteor. Soc., 96, 1647-1665, https://doi.org/10.1175/BAMS-D-14-00089.1.

Menkes, C. E., M. Lengaigne, J. Vialard, M. Puy, P. Marchesiello, S. Cravatte, and G. Cambon, 2014: About the role of westerly wind events in the possible development of an El Niño in 2014. Geophys. Res. Lett., 41, 6476-6483, https://doi.org/10.1002/ 2014 GL061186.

Meyers, G., J. R. Donguy, and R. K. Reed, 1986: Evaporative cooling of the western equatorial Pacific Ocean by anomalous winds. Nature, 323, 523-526, https://doi.org/10.1038/323523a0.

Nerem, R. S., B. D. Beckley, J. T. Fasullo, B. D. Hamlington, D. Masters, and G. T. Mitchum, 2018: Climate-change-driven accelerated sea-level rise detected in the altimeter era. Proc. Natl. Acad. Sci. USA, 115, 2022-2025, https://doi.org/10.1073/ pnas.1717312115.

Qiu, B., W. Miao, and P. Müller, 1997: Propagation and decay of forced and free baroclinic Rossby waves in off-equatorial oceans. J. Phys. Oceanogr., 27, 2405-2417, https://doi.org/ 10.1175/1520-0485(1997)027<2405:PADOFA > 2.0.CO;2.

Rayner, N. A., D. E. Parker, E. B. Horton, C. K. Folland, L. V. Alexander, D. P. Rowell, E. C. Kent, A. Kaplan, 2003: Global analyses of sea surface temperature, sea ice, and night marine air temperature since the late nineteenth century. J. Geophys. Res., 108, 4407, https://doi.org/10.1029/2002JD002670.

Reynolds, R. W., N. A. Rayner, T. M. Smith, D. C. Stokes, and W. Wang, 2002: An improved in situ and satellite SST analysis for climate. J. Climate, 15, 1609-1625, https://doi.org/10.1175/ 1520-0442(2002)015<1609:AIISAS > 2.0.CO;2.

Schneider, N., A. J. Miller, and D. W. Pierce, 2002: Anatomy of North Pacific decadal variability. J. Climate, 15, 586-605, https://doi.org/ 10.1175/1520-0442(2002)015<0586:AONPDV>2.0.CO;2.

Smith, R., and Coauthors, 2010: The Parallel Ocean Program (POP) reference manual: Ocean component of the Community Climate System Model (CCSM) and Community Earth System Model (CESM). Los Alamos National Laboratory LAUR-10-01853, 140 pp., http://www.cesm.ucar.edu/models/ cesm1.2/pop2/doc/sci/POPRefManual.pdf.

Sweet, W., J. Park, J. Marra, C. Zervas, and S. Gill, 2014: Sea level rise and nuisance flood frequency changes around the United States. NOAA Tech. Rep. NOS CO-OPS 073, 58 pp., https:// tidesandcurrents.noaa.gov/publications/NOAA_Technical_ Report_NOS_COOPS_073.pdf.

, R. E. Kopp, C. P. Weaver, J. Obeysekera, R. M. Horton, E. R. Thieler, and C. Zervas, 2017: Global and regional sea level rise scenarios for the United States. NOAA Tech. Rep. NOS CO-OPS 083, 75 pp., https://tidesandcurrents.noaa.gov/ publications/techrpt83_Global_and_Regional_SLR_Scenarios_ for_the_US_final.pdf.

Tamisiea, M. E., E. M. Hill, R. M. Ponte, J. L. Davis, I. Velicogna, and N. T. Vinogradova, 2010: Impact of self-attraction and loading on the annual cycle in sea level. J. Geophys. Res., 115, C07004, https://doi.org/10.1029/2009JC005687.

Taylor, K. E., R. J. Stouffer, and G. A. Meehl, 2012: An overview of CMIP5 and the experiment design. Bull. Amer. Meteor. Soc., 93, 485-498, https://doi.org/10.1175/BAMS-D-11-00094.1.

Thompson, L., and C. A. Ladd, 2004: The response of the North Pacific Ocean to decadal variability in atmospheric forcing: Wind versus buoyancy forcing. J. Phys. Oceanogr., 34, 
1373-1386, https://doi.org/10.1175/1520-0485(2004)034<1373: TROTNP $>2.0 . C O ; 2$.

Thompson, P. R., M. J. Widlansky, M. A. Merrifield, J. M. Becker, and J. J. Marra, 2019: A statistical model for frequency of coastal flooding in Honolulu, Hawaii, during the 21st century. J. Geophys. Res. Oceans, 124, 2787-2802, https://doi.org/ 10.1029/2018JC014741.

Timmermann, A., S. McGregor, and F. F. Jin, 2010: Wind effects on past and future regional sea level trends in the southern IndoPacific. J. Climate, 23, 4429-4437, https://doi.org/10.1175/ 2010JCLI3519.1.

Vinogradova, N. T., R. M. Ponte, M. E. Tamisiea, J. L. Davis, and E. M. Hill, 2010: Effects of self-attraction and loading on annual variations of ocean bottom pressure. J. Geophys. Res. 115, C06025, https://doi.org/10.1029/2009JC005783.

Widlansky, M. J., A. Timmermann, S. McGregor, M. F. Stuecker, and W. Cai, 2014: An interhemispheric tropical sea level seesaw due to El Niño Taimasa. J. Climate, 27, 1070-1081, https://doi.org/10.1175/JCLI-D-13-00276.1.

-, , and W. Cai, 2015: Future extreme sea level seesaws in the tropical Pacific. Sci. Adv., 1, e1500560, https://doi.org/ 10.1126/sciadv.1500560.

_- and Coauthors, 2017: Multimodel ensemble sea level forecasts for tropical Pacific islands. J. Appl. Meteor. Climatol., 56, 849-862, https://doi.org/10.1175/JAMC-D-16-0284.1.
H. Annamalai, S. B. Gingerich, C. D. Storlazzi, J. J. Marra, K. I. Hodges, B. Choy, and A. Kitoh, 2019: Tropical cyclone projections: Changing climate threats for Pacific Island defense installations. Wea. Climate Soc., 11, 3-15, https://doi.org/ 10.1175/WCAS-D-17-0112.1.

Wilks, D. S., 2006: Statistical Methods in the Atmospheric Sciences. 2nd ed. Elsevier, 627 pp.

Wyrtki, K., 1984: The slope of sea level along the equator during the 1982/1983 El Niño. J. Geophys. Res., 89, 10 419-10 424, https://doi.org/10.1029/JC089IC06P10419.

Xie, S.-P., W. T. Liu, Q. Liu, and M. Nonaka, 2001: Far-reaching effects of the Hawaiian Islands on the Pacific Oceanatmosphere system. Science, 292, 2057-2060, https://doi.org/ 10.1126/science.1059781.

Yin, J., S. M. Griffies, and R. J. Stouffer, 2010: Spatial variability of sea level rise in twenty-first century projections. J. Climate, 23, 4585-4607, https://doi.org/10.1175/2010JCLI3533.1.

Yoon, H., M. J. Widlansky, and P. R. Thompson, 2018: Nu'a Kai: Flooding in Hawaii caused by a "stack" of oceanographic process [in "State of the Climate in 2017"]. Bull. Amer. Meteor. Soc., 99 (8), S88-S89, https://doi.org/10.1175/ 2018BAMSStateoftheClimate.1.

Yu, L., and R. A. Weller, 2007: Objectively analyzed air-sea heat fluxes for the global ice-free oceans (1981-2005). Bull. Amer. Meteor. Soc., 88, 527-540, https://doi.org/10.1175/BAMS-88-4-527. 